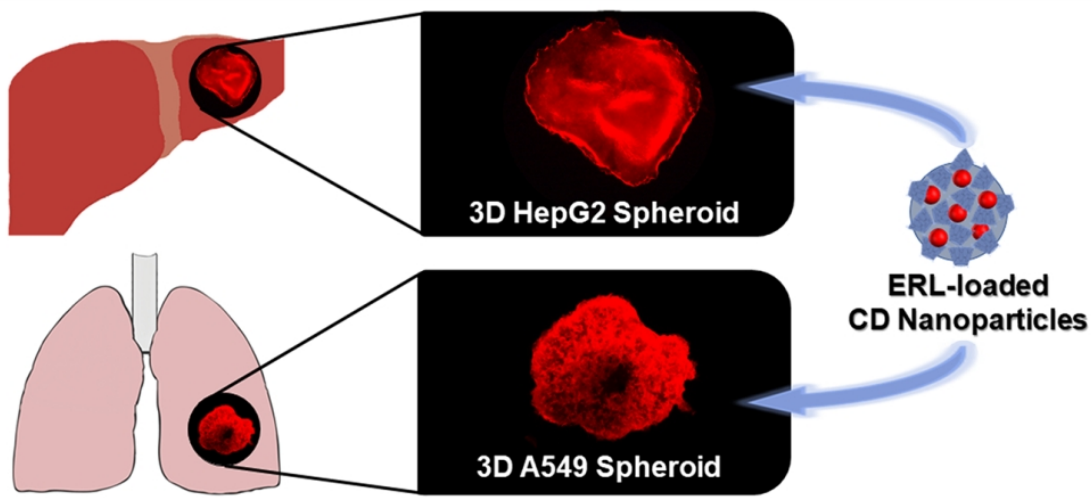
.

.
5

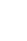

.




\section{Erlotinib Entrapped in Cholesterol-Depleting Cyclodextrin Nanoparticles Shows Improved Antitumoral Efficacy in 3D Spheroid Tumors of the Lung and the Liver}

Gamze Varan ${ }^{a}$, Safiye Akkın ${ }^{\text {a }}$, Nurbanu Demirtürk ${ }^{\mathrm{a}}$, Juan M. Benito ${ }^{\mathrm{b}}$ and Erem Bilensoy*

a Department of Pharmaceutical Technology, Faculty of Pharmacy, Hacettepe University, 06100, Ankara, Turkey; ${ }^{b}$ Institute for Chemical Research, CSIC - University of Sevilla, Av. Américo Vespucio 49, Sevilla 41092, Spain e-mail: eremino@hacettepe.edu.tr *corresponding author 


\section{Erlotinib Entrapped in Cholesterol-Depleting Cyclodextrin Nanoparticles Shows Improved Antitumoral Efficacy in 3D Spheroid Tumors of the Lung and the Liver}

Erlotinib (ERL), a tyrosine kinase inhibitor approved for therapeutic use in nonsmall cell lung cancer is further researched for eventual liver cancer treatment. However, conventional ERL has important bioavailability problems resulting from oral administration, poor solubility and gastrointestinal degradation into inactive metabolites. Alternative administration routes and nanoparticulate drug delivery systems are studied to prevent or reduce these drawbacks. In this study, ERL-loaded CD nanosphere and nanocapsule formulations capable of cholesterol depletion in resistant cancer cells were evaluated for ERL delivery. Drug loading and release profile depended largely on the surface charge of nanoparticles. Antiproliferative activity data obtained from 2D and 3D cell culture models demonstrated that polycationic $\beta C D$ nanocapsules were the most effective formulation for ERL delivery to lung and liver cancer cells. 3D tumor uptake studies further revealed that nanocapsule formulations penetrated deeper into the tumor through the multilayered cells. Furthermore, all formulations were able to extract membrane cholesterol from lung and liver cancer cell lines, indicating induction of apoptosis and overcoming drug resistance. In conclusion, given their tumoral penetration and cell membrane cholesterol depletion abilities, amphiphilic CD nanocapsules emerge as promising alternatives to improve the safety and efficiency of ERL treatment of both liver and lung tumors.

Keywords: 3D multicellular spheroid; amphiphilic cyclodextrin; cholesterol; erlotinib; nanoparticle; hepatocellular carcinoma; non-small cell lung carcinoma

\section{Introduction}

Cancer is a complex disease that can be defined as the uncontrolled division and reproduction of cells in an organ or tissue. Tumor microenvironment contains different stromal cells besides malignant cells and this complex area requires special and selective treatment strategies [1]. These strategies are surgery, chemotherapy, 
radiotherapy, phototherapy, immunotherapy, hormone therapy and targeted therapy. Targeted therapy is expected to enhance selectivity of the therapeutic effect on tumors and avoid adverse effects on non-tumoral tissues [2].

Erlotinib hydrochloride (ERL) is a tyrosine kinase inhibitor drug belonging to BCS Class II, characterized by high permeability and low solubility. ERL is known to target epidermal growth factor receptors (EGFR) [3]. It was approved in 2004 for nonsmall cell lung cancer (NSCLC) and the approval was modified in 2016 for advanced or metastatic pancreatic cancer treatment by U.S. Food and Drug Administration (FDA) $[4,5]$. ERL is available in oral tablet form under the trade name Tarceva ${ }^{\circledR}$ in the market. There are several completed and ongoing clinical studies on the use of ERL, which has a broad spectrum of anticancer efficacy, focusing on the treatment of breast, liver and colorectal cancers. As with most anticancer drugs, poor water solubility brings many drawbacks, eventually leading to a decrease in effectiveness of treatment. ERL has important bioavailability problems resulting from poor solubility and also the formation of $60 \%$ of ineffective metabolite in the gastrointestinal system as a result of oral administration [6]. In addition, diarrhea, rash, anemia and ocular lesions have been reported as side effects of ERL in clinical use [3].

Nanoparticles are remarkable platforms for use in different cancer treatments by eliminating or reducing the side effects of many drugs and / or biomolecules. Today, there are several anticancer drug preparations formulated with different nanocarriers in the market and successful results are obtained in the clinic $[7,8]$ with these nanomedicines and their follow-on products; nanosimilars. In the meantime, new formulation strategies have been developed for ERL to improve efficacy and to reduce side effects [9-13]. There are clinical trials at various stages focusing on ERL therapeutic indication as well as formulation. However, there are no nanomedicines for 
ERL on the market yet. Numerous different systems based on PLGA, albumin or liposomes are being developed for the use of targeted ERL delivery [13-15].

Cyclodextrins (CDs) are cyclic oligosaccharides obtained through enzymatic degradation of starch, consisting of $\alpha(1 \rightarrow 4)$-linked glucopyranose units. The cyclic structure of most prominent CD examples (namely $\alpha, \beta$ and $\gamma$-CD consisting of 6,7 and 8 glucopyranose subunits, respectively) defines a relatively hydrophobic cavity of nanometric dimensions that readily host non-polar guests of appropriate size [16]. As a consequence, CDs have been profusely employed to improve the bioavailability of a number of poorly soluble drugs [17]. Amphiphilic CDs, like other CD derivatives, have been synthesized to manipulate the properties of natural CDs such as increasing the interaction with biological membranes and loading capacity for hydrophobic molecules. In addition, amphiphilic CDs have the ability to spontaneously self-assemble into nanoparticles in aqueous media. This feature plays an important role in the use of amphiphilic CDs as drug delivery systems [18,19]. Amphiphilic CD nanoparticles in different forms have been reported as safe and effective drug delivery systems for a number of anticancer molecules/genes with bioavailability problems [20-32].

Tumorigenesis is a biological process controlled by extracellular matrix (ECM), cancer cell, and stroma. In this biological process, the development and metastasis of cancer cells depend on many factors, such as growth factors, hormones, and other cells within the ECM [33]. These spherical tumors formed in vitro can be considered as small microtumors because they are self-assembling cancer structures formed in a hierarchical arrangement where intercellular contacts form a 3-dimensional (3D) spherical structure $[32,34]$. Cell-based assays are the main tool for assessing the potential efficacy of a new compound in drug discovery. In order to obtain the most reliable results, the cell culture model used as the test platform should work similarly to the cells in vivo. 
Cholesterol is one of the main components in the structure of the cell membrane and plays an important role in cell viability. However, clinical and experimental findings show that cholesterol metabolism may play an important role in carcinogenesis and tumor development. The amount of cholesterol in the membrane of cancer cells is higher than that in healthy cells. Moreover, it is known that anticancer drug resistant tumor cells contain more cholesterol in their membranes than drug sensitive cancer cells $[35,36]$. The inherent ability of certain cyclodextrins to extract cholesterol from cell membranes provides the opportunity to use them in the treatment of cholesterol-related diseases, overcoming of drug resistance in cancer being among the most important potential outcome of this unique property.

The aim of the present study was to design and evaluate nanospheres and nanocapsules based on amphiphilic $\alpha$ - and $\beta-\mathrm{CD}$ in order to increase the tumoral penetration, intracellular delivery and anticancer efficacy of ERL. For this purpose, three different amphiphilic $\mathrm{CD}$ derivatives, namely 6 OCapro- $\alpha \mathrm{CD}$, 6OCapro- $\beta C D$ and PC $\beta C D C 6$ were synthesized and used to prepare nanospheres and nanocapsules. Blank and ERL-loaded nanoparticles were formulated and characterized in terms of mean particle size, polydispersity index, zeta potential, ERL loading capacity and in vitro release profile. Safety studies of blank nanoparticles were performed on L929 mouse fibroblast cells and the anticancer activities of ERL-loaded nanoparticles were determined against A549 human lung cancer and HepG2 hepatocellular carcinoma cell lines by both $2 \mathrm{D}$ and $3 \mathrm{D}$ cell culture methods. The cellular uptake and tumoral penetration imaging studies were performed with fluorescent nanoparticles on 3D tumor model. In addition, the developed amphiphilic CD nanoparticles were evaluated for their capacity of cholesterol extraction from lung and liver cancer cells. 


\section{Materials and Methods}

\section{Materials}

Nonionic amphiphilic CDs 6OCaproßCD (Mw: $1822 \mathrm{~g} / \mathrm{mol}$ ) [37] and 6OCaproaCD (detailed synthesis and characterization data were given in the Supplemental file) (Mw: $1562 \mathrm{~g} / \mathrm{mol}$ ) and polycationic amphiphilic CD PC $\beta C D C 6$ [38] (Mw: $3178 \mathrm{~g} / \mathrm{mol}$ ) were synthesized and purified according to previously reported procedure. Methyl- $\beta C D$ (Cavasol ${ }^{\circledR}$ W7 M Pharma) was purchased Wacker Chemie AG, USA. Erlotinib hydrochloride (Mw: $429.9 \mathrm{~g} / \mathrm{mol}$ ) was a kind gift of Nobel Pharmaceuticals, Turkey purchased from Hetero Labs (Gaddapotharam, India). Dialysis Tubing Cellulose Membrane (avg. flat width 25mm, MWCO: $14000 \mathrm{Da}$ ) was purchased from Sigma \&Aldrich, Germany. A549 (ATCC® CCL-185 ${ }^{\mathrm{TM}}$ ) and HepG2 (ATCC® HB-8065'TM) cell lines were purchased from American Type Culture Collection (ATCC). Poly(2hydroxyethyl methacrylate) (poly-HEMA) (P3932) was purchased from Sigma-Aldrich, Germany. Matrigel ${ }^{\circledR}$ Basement Membrane Matrix (356234) was purchased from Corning, USA. Cholesterol quantitation kit (MAK043) was purchased from SigmaAldrich, USA. All other chemicals used were of analytical grade and obtained from Sigma \& Aldrich, USA. Ultrapure water was obtained from Millipore Simplicity 185 Ultrapure Water System (Millipore, France).

\section{Preparation of Blank and Erlotinib Loaded Amphiphilic Cyclodextrin Nanoparticles}

Blank or ERL-loaded nanosphere and nanocapsules were prepared using the nanoprecipitation method [30,39]. Briefly, for blank nanospheres, amphiphilic CD was dissolved in ethanol $(1 \mathrm{mg} / \mathrm{mL})$. Then, this organic solution $(1 \mathrm{~mL})$ was added dropwise into aqueous phase $(2 \mathrm{~mL})$ by dispenser tip under magnetic stirring at room 
temperature. The organic solvent was then evaporated under vacuum at $40^{\circ} \mathrm{C}$ to obtain final nanosphere dispersions $(2 \mathrm{~mL})$. ERL-loaded nanoparticles were prepared with the same method with ERL completely dissolved in organic phase $(0.1 \mathrm{mg} / \mathrm{mL})$.

On the other hand, to obtain the blank or ERL-loaded nanocapsules, the same technique was used with the exception of an oil phase of Miglyol $812(10 \mu \mathrm{L})$ which was added to the organic phase consisting of the CD and ERL.

\section{Size Distribution and Surface Charge of Nanoparticles}

Blank or ERL-loaded amphiphilic CD nanoparticles were characterized in terms of mean particle size, polydispersity index and zeta potential. Mean particle size (nm), polydispersity index (PDI) and zeta potential of blank or ERL-loaded amphiphilic CD nanoparticles were determined by Dynamic Light Scattering (DLS) technique (Malvern Zetasizer NanoZS; Malvern Instruments, UK). All formulations were measured at an angle of $173^{\circ}$ for particle size and $12^{\circ}$ for zeta potential $(\mathrm{mV})$ at room temperature by triplicate.

\section{Encapsulation Efficiency of Amphiphilic Cyclodextrin Nanoparticles}

The encapsulation efficiency of ERL into amphiphilic CD nanospheres and nanocapsules was quantified directly by a validated HPLC method [40]. Briefly, ERLloaded nanoparticle formulations were centrifuged at $5000 \mathrm{rpm}$ for 10 minutes to remove free drug. Supernatant was collected and lyophilized for $24 \mathrm{~h}$. The lyophilized nanoparticle powder was dissolved in Dimethyl Sulfoxide (DMSO) to quantify the amount of nanoparticle bound ERL. For the quantification, a C18 Purospher $\Re$ STAR analytical column (250 mm x $4.6 \mathrm{~mm}, 5 \mu \mathrm{m})$ was used for HPLC analysis. The mobile phase was composed of ammonium acetate buffer $(\mathrm{pH} 4.0)$ and acetonitrile $(65: 35 \mathrm{v} / \mathrm{v})$. Mobile phase was used as solvent in all samples for HPLC analyses. ERL absorbance 
was measured at $247 \mathrm{~nm}$ using diode array detector with flow rate of $1 \mathrm{~mL} / \mathrm{min}$ and injection volume was $20 \mu \mathrm{L}$.

Drug loading capacity was calculated using the following equation (1) to express the percentage of ERL bound to nanoparticles.

$$
\text { Associated drug }(\%)=\frac{\text { Experimental drug loading }}{\text { Initial drug quantity }} \times 100
$$

\section{Physical Stability of ERL-loaded Nanoparticles}

The physical stability of ERL-loaded nanoparticles was evaluated after storage at $+4{ }^{\circ} \mathrm{C}$ for up to 30 days. At time points of $0,1,4,7$ and 30 days all nanoparticles were characterized for mean particle size, PDI, and surface charge by using DLS technique. The measurements were performed in triplicate at room temperature.

\section{Drug Release Studies}

In vitro drug release profile of ERL from the amphiphilic CD nanoparticles were determined by using dialysis membrane $(\mathrm{MwCO}=14.000 \mathrm{Da})$ method. For this purpose, ERL-loaded nanoparticle dispersion was prepared freshly, and $1 \mathrm{~mL}$ of nanoparticle added into dialysis membrane bag. The bag was transferred into $20 \mathrm{~mL}$ of phosphate buffer saline (PBS, $\mathrm{pH} 7.4)$ with $0.1 \%(\mathrm{v} / \mathrm{v})$ Tween 80 . The process was conducted under sink conditions at $37^{\circ} \mathrm{C}$ and shaking with $50 \mathrm{rpm}$. At specific time points, sample $(0.5 \mathrm{~mL})$ was collected from the medium and replaced with fresh PBS at same volume and temperature. The samples were diluted equally with the mobile phase used in the HPLC method for analysis. Drug release percentage over time of the ERLloaded amphiphilic CD nanocarriers was calculated and plotted for each formulation $[13,14]$. 


\section{Cell Culture Studies}

All cell lines were cultured in the same conditions in Dulbecco's modified Eagle's medium (DMEM) supplemented with 10\% fetal bovine serum (FBS), penicillin (100 units $/ \mathrm{mL})$ and streptomycin $(100 \mu \mathrm{g} / \mathrm{mL})$. The cultures were maintained at $37^{\circ} \mathrm{C}$ in a humidified 5\% CO2 incubator.

\section{Determination of Safety of Blank Amphiphilic CD Nanoparticle}

In order to evaluate the safety of blank amphiphilic CD nanospheres and nanocapsules, metabolic activity assay was performed on L929 mouse fibroblast cells by WST-1 (Water-soluble Tetrazolium 1) assay. L929 healthy mouse fibroblast cells are the cell line recommended by the United States Pharmacopoeia (USP) 87 and ISO 109935:2009 [41] for the in vitro determination of toxicity in mammalian cell culture of polymeric materials that will directly or indirectly contact the patient. For this purpose, L929 cells were seeded in 96-well tissue culture plates at a density of 5 x 104 cells/well $(100 \mu \mathrm{L})$ in DMEM. After 24h, culture medium was replaced with different concentration of blank nanoparticles within fresh complete medium and incubated $48 \mathrm{~h}$. After incubation, WST-1 assay was applied. Finally, optical density (OD) was determined by microplate reader at $450 \mathrm{~nm}$ and cell proliferation was calculated for each treatment group and non-treatment control group.

\section{Determination of $I_{50}$ Value of Erlotinib Solution and Erlotinib Loaded} Amphiphilic Cyclodextrin Nanoparticles

The $\mathrm{IC}_{50}$ value of ERL and ERL-loaded nanoparticle formulations was determined on A549 human lung carcinoma cells and HepG2 human hepatocellular carcinoma cells. For this purpose, cells were seeded in 96-well tissue culture plates at a density of $5 \mathrm{x}$ $10^{4}$ cells/well $(100 \mu \mathrm{L})$ in DMEM, separately. After $24 \mathrm{~h}$, cell media was replaced with 
different concentrations $(2,10,25,50$ and $100 \mu \mathrm{M})$ of ERL solutions or ERL-loaded nanoparticle formulations in DMEM. After 24 and $48 \mathrm{~h}$ incubation time, cell viability was determined by WST-1 assay. Cells treated with the DMEM were considered as control and $100 \%$ viable. The $\mathrm{IC}_{50}$ value of ERL solution and each ERL-loaded nanoparticle formulations were calculated by using GraphPad Prism version 6 . According to the results of the $\mathrm{IC}_{50}$ study, 1:16(v:v) concentration (equivalent to 7.8 uM ERL) was selected as working concentration in all cell culture studies.

\section{Cytotoxicity of Blank and ERL-Loaded Amphiphilic CD Nanoparticles}

In order to determine the anticancer activity of blank or ERL-loaded amphiphilic CD nanoparticles against A549 and HepG2 cells. Firstly, cells (5 x 104 cells/well) were seeded in DMEM $(100 \mu \mathrm{L})$ and incubated for $24 \mathrm{~h}$. Then, media containing CD nanoparticles was added to the cells and incubated for $48 \mathrm{~h}$. The cell proliferation was determined by WST-1 assay as detailed above.

\section{Antitumoral Activity of ERL-loaded CD Nanoparticles on 3D Spheroid Tumor Culture}

Antitumoral efficiency of ERL-loaded nanoparticles were performed in 3D multicellular tumor spheroids against A549 and HepG2 cell lines. For this purpose pre-coated plates with poly-HEMA were prepared as described previously [32,42]. Then, A549 or HepG2 cell suspension of $5 \times 10^{4}$ cells $/ \mathrm{mL}$ with $3 \%$ Matrigel ${ }^{\circledR}$ Basement Membrane Matrix (356234, Corning) of total volume was prepared and $200 \mu \mathrm{L}$ cell suspension was added in pre-coated plate. The plates were centrifuged at $1000 \mathrm{rpm}$ for $10 \mathrm{~min}$ and gently allowed to incubate to conserve the cell clusters in wells. Culture media was refreshed every 2 days by replacing $100 \mu \mathrm{L}$ of the media. The spheroid formation was examined microscopically. After ten days, culture medium was replaced with ERL-loaded CD 
nanoparticles and cell viability was determined with WST-1 assay after 48 and $72 \mathrm{~h}$.

\section{Tumoral Penetration Properties of ERL-Loaded Amphiphilic CD Nanoparticles} on 3D Tumor Model

In order to determine tumoral penetration of nanoparticles, Nile Red (NR) loaded amphiphilic CD nanoparticles were prepared by the nanoprecipitation method used to prepare nanoparticles. Firstly, a stock solution of NR was prepared in ethanol $(1 \mathrm{mg} / \mathrm{mL})$ and $100 \mu \mathrm{L}$ NR solution was added into the organic phase of $1 \mathrm{~mL}$ volume. After ten days of seeding of 3D tumor spheroids, $100 \mu \mathrm{L}$ DMEM was replaced from each well. Then, $100 \mu \mathrm{L}$ of NR-loaded nanoparticles within DMEM was added into the spheroids. Later incubating for $6 \mathrm{~h}$, media was removed, and spheroids were washed 3 times with PBS to remove free nanoparticles or dye and further imaged with a fluorescence microscope.

\section{Cholesterol Depletion Ability of Amphiphilic Cyclodextrin Nanoparticles}

Cholesterol depletion activity of amphiphilic CD nanoparticles in A549 and HepG2 cells was determined with the Sigma MAK043 cholesterol assay kit. First, cells were seeded into 6-well plates $\left(10^{6}\right.$ cells $\left./ \mathrm{mL}\right)$ separately and incubated for $24 \mathrm{~h}$. After that, the media on the cells was replaced with new media containing the blank CD nanoparticle formulation and the cells were incubated for $24 \mathrm{~h}$. Cells incubated with methyl- $\beta C D$ were used as positive control group. The manufacturer's protocol was applied at the end of the appropriate incubation periods.

\section{Statistical Analysis}

All statistical analyses were performed by Student's t-test and ANOVA test using GraphPad Prism version 6 (San Diego, CA, USA). $\mathrm{p}<0.05$ was considered to denote a 
statistically significant difference.

\section{Results \\ In vitro Characterization of Blank and Erlotinib Loaded Amphiphilic Cyclodextrin Nanoparticles}

All amphiphilic CD nanoparticle formulations were prepared by the nanoprecipitation method [19,31]. The physical characterization data of blank and ERL-loaded amphiphilic CD nanospheres and nanocapsules are shown in Table 1.

The mean particle size in all blank nanosphere formulations was determined to be between 100 to $300 \mathrm{~nm}$ with narrow polydispersity (PDI < 0.4). Blank 6OCaproßCD and PC $\beta C D C 6$ nanospheres systematically resulted smaller than 6OCapro $\alpha \mathrm{CD}$ ones. As expected, all nanocapsules formulations were larger than the nanospheres because the oil droplet formed during the spontaneous spherical crystallization process acts as a template, effectively determining the final nanocapsule size. When the zeta potential values are examined, it is seen that $6 \mathrm{OCapro \alpha CD}$ and $6 \mathrm{OCapro} \beta \mathrm{CD}$ have negative and PC $\beta C D C 6$ derivative has positive surface charge in aqueous environment as expected $[19,31,32,37,39]$.

In addition, as depicted in Table 1, the mean particle sizes of ERL-loaded nanoparticles were determined to be between $88-270 \mathrm{~nm}$. Regardless of their cationic or anionic nature, there was no significant change in the surface charge of nanoparticles, homogeneity being slightly improved in most of cases upon ERL encapsulation. Interestingly, there was a generalized decrease in the particle size of most of formulations after drug loading. NP shrinking might be indicative of a more efficient hydrophobic-driven compaction, that usually leads to a higher encapsulation efficiency 
[43]. In turn, these results point to the fact that ERL is mostly included into the NP core rather than adsorbed on the surface of the nanoparticles.

\section{Encapsulation Efficiency of Amphiphilic CD Nanoparticles}

The amount of drug entrapped in the nanoparticle formulations was determined directly by HPLC analysis and the results are shown in Figure 1. Drug loading efficiencies for all nanoparticle formulations vary in a wide range (between $49 \%$ and $87 \%$ ) depending on CD type and formulation type. The encapsulation efficacy increases in order 6 OCapro $\beta \mathrm{CD}<6 \mathrm{OCapro} \alpha \mathrm{CD}<\mathrm{PC} \beta \mathrm{CDC} 6$ for both nanospheres and nanocapsules ( $\mathrm{p}$ $<0.05)$. In addition, nanocapsules have higher loading efficiency than nanospheres, which is in accordance with literature when lipophilic drug encapsulation is concerned. The oily core provides a better reservoir for lipophilic molecules than the matrix structure of the nanospheres [43-45].

\section{Short-Term Physical Stability of ERL-loaded Amphiphilic CD Nanoparticles}

Physical stability of nanoparticles upon storage is an important critical quality parameter. Nanoparticles should maintain their major attributes like particle size distribution and surface charge for a reasonable period of time to allow controlled release of the encapsulated drug and show the therapeutic effect required from the drug delivery system. To evaluate the short-term storage stability, ERL-loaded nanosphere and nanocapsule dispersions in water $(0.5 \mathrm{mg} \mathrm{CD} / \mathrm{mL})$ were stored at $+4{ }^{\circ} \mathrm{C}$ for one month. The mean particle size $(\mathrm{nm})$, polydispersity index and zeta potential $(\mathrm{mV})$ of nanoparticles were measured at five time points. The data obtained from the physical stability studies of ERL-loaded amphiphilic CD nanoparticles prepared using nanoprecipitation method are shown in Figure 2. 
None of the changes in particle size over time were found statistically significant $(p>0.05)$ and aggregation did not occur in the formulations. Furthermore, there was no significant difference in PDI of the formulations over the time $(p>0.05)$. According to the results, it can be said that ERL-loaded amphiphilic CD nanosphere and nanocapsule formulations remained stable for 30 days and these amphiphilic CD derivatives are suitable polymers for preparing a nanoparticulate delivery system for ERL.

As depicted in Figure $2 b$, there were no significant differences in zeta potential changes of amphiphilic CD nanoparticles during storage for 30 days. It has been observed that nanoparticles maintain surface charge during storage at $+4^{\circ} \mathrm{C}$. In this study, the effect of the surface charge of the nanoparticles on cellular uptake and anticancer activity was also examined. Therefore, the stability of the nanoparticles in terms of zeta potential allow to evaluate the effect of nanoparticle surface charge on anticancer activity and cellular uptake properties.

\section{Drug Release Studies}

Targeted nanoparticles are expected to release the drug entrapped in their structure for a certain period of time in a controlled manner. Although particles in the nanometer range have a large surface area that accelerates the release of the drug, polymer structure and surface modifications as well as the affinity of the encapsulated drug to the polymer host can prolong the release of the drug. Burst release is expected for the drug that is adsorbed on the surface of the particles followed by a more gradual release of the drug entrapped inside mostly depending on the diffusion rate. On the other hand, drug release from nanocapsules is mainly controlled by the oil-water partition coefficient of the encapsulated drug.

The ERL release profile of amphiphilic CD nanocapsules and nanospheres was obtained by dialysis membrane method under sink conditions. The data obtained by 
HPLC analysis are shown in Figure 3. The study was carried on for $12 \mathrm{~h}$ and peak areas were calculated from sample: mobile phase mixture at 1:1 (v/v) ratio. Anionic 6OCapro $\beta C D$ nanosphere and nanocapsules showed the fastest burst release, with nearly $50 \%$ of encapsulated drug being liberated in one hour, while the other CD nanoparticles released this amount in two hours. The slowest release was obtained with cationic PC $\beta C D C 6$ nanospheres. At the end $12 \mathrm{~h}$ of release studies, it was shown that PC $\beta C D C 6$ nanospheres had the slowest release behavior compared to other groups statistically with t-tests $(\mathrm{p}<0.05)$.

\section{Cell Culture Studies}

\section{Determination of Safety of Blank Amphiphilic CD Nanoparticles}

The effect of blank amphiphilic CD nanoparticles on cell viability in healthy cells was compared with the control group. According to the results shown in Figure 4, blank amphiphilic CD nanoparticles did not cause any toxicity in the healthy cells $(\mathrm{p}>0.05)$. Cell viability is above $85 \%$ for all nanoparticle formulations. These results show that the inherent toxicity of amphiphilic CD nanoparticles on healthy L929 cells is minimal.

\section{Determination of $I_{50}$ of ERL solution and ERL-loaded Nanoparticles on A549 and HepG2 cell lines}

The half-maximal inhibitory concentration $\left(\mathrm{IC}_{50}\right)$ values of ERL solution in DMSO and ERL-loaded into nanoparticles were determined in A549 and HepG2 cells with WST-1 assays for 24 and $48 \mathrm{~h}$. The water-soluble formazan crystal formation was quantified spectrophotometrically at $450 \mathrm{~nm}$ using a microplate reader. According to Table 2 , it can be said that the sensitivity of cancer cell lines to ERL is different and the nanoparticle formulations increase drug sensitivity and lower $\mathrm{IC}_{50}$ for ERL especially after $48 \mathrm{~h}$. 
All formulations induced a more efficient cell proliferation inhibition at $48 \mathrm{~h}$ than at $24 \mathrm{~h}$ incubation time in both cells. Though, this efficiency improvement was larger for ERL-encapsulated than for the non-encapsulated control. Besides, it was determined by the $\mathrm{IC}_{50}$ value that the anticancer activities of nanoparticle formulations prepared from different $\mathrm{CD}$ derivatives are different from each other. According to the results, the PC $\beta C D C 6$ derivative has the lowest $\mathrm{IC}_{50}$ value in both cell lines. Interestingly, the $\mathrm{IC}_{50}$ value of the 6OCaproaCD nanospheres was higher than the drug solution at $24 \mathrm{~h}$ in both cell lines suggesting a much slower onset of the anticancer drug inside the cells.

However, after $48 \mathrm{~h}$, the number of viable cells decreased significantly for all formulations indicating time-dependent cytotoxicity.

Appropriate dose of nanoparticle formulations for use in subsequent cell culture studies was therefore selected as $1 / 16(\mathrm{v}: \mathrm{v})$ dilution rate corresponding to $7.8 \mu \mathrm{M}$ that is above the $\mathrm{IC}_{50}$ values determined for ERL solution in both cell types.

\section{Anticancer Efficacy of Blank and ERL-loaded Amphiphilic CD Nanoparticles}

The anticancer activity of blank or ERL-loaded nanospheres and nanocapsules was determined by WST-1 assay on cell viability in lung and liver cancer cell lines. As seen in Figures 5a and 5b, ERL-loaded PC BCDC6 nanocapsules induced the lowest cell viability. Furthermore, even the least active formulations $(p<0.05)$ was found to induce higher cell inhibition than the conventional ERL solution for both cell lines.

A closer analysis of these data indicated that ERL-loaded nanoparticles exhibit disparate anticancer activity in lung and liver cancer cell lines. Nanocapsule formulations of all amphiphilic CD derivatives caused higher cell death in HepG2 cells than nanospheres. In lung cancer A549 cells it was found that the PC $\beta$ CDC6 nanocapsule formulation is more effective than nanosphere formulations. The situation is opposite for the anionic 6Capro $\alpha-$ and $\beta-\mathrm{CD}$ nanoparticles. Moreover, the 
nanoparticle formulations have been found to cause more cell death in A549 cells than HepG2 cells.

\section{Cholesterol Depletion Ability of Amphiphilic Cyclodextrin Nanoparticles}

The effect of amphiphilic CD nanoparticles on total cholesterol amount in cancer cells was determined with the commercially available cholesterol kit, and the data obtained are shown in Figure 6. Methyl- $\beta$ CD that is a known cholesterol depletion agent was used as positive control. As depicted in Figure 6, all nanoparticle formulations depleted significant cholesterol amounts in both cancer cell lines. In addition, in the study with the same number of cells, it was observed that the total cholesterol content of A549 cells was 1.8 times higher than HepG2.

According to the results, it can be said that neither the nanoparticle formulation type (nanosphere or nanocapsule) nor their $\zeta$-potential play a relevant role on cholesterol extraction abilities. Furthermore, when the amphiphilic CD derivatives were compared, it was observed that the groups treated with amphiphilic $\beta$-CD derivatives (6OCapro $\beta$ and PC $\beta C D C 6$ ) had lower cholesterol content, especially in A549 cells. This result is similar in HepG2 cells treated with amphiphilic CD nanocapsules. Promisingly, cholesterol depletion activity of all CD nanoparticulate groups were higher than that of the reference Methyl- $\beta$ CD apart from polycationic $-\beta$ CDC6 that showed an equivalent cholesterol extraction capacity to the reference.

\section{Antitumoral Activity of ERL-loaded Amphiphilic CD Nanoparticles on 3D} Spheroid cell cultures

Among the different formulations explored, PC BCDC6 nanocapsules achieved highest anticancer effect. Cell proliferation inhibition increases at prolonged incubation times for all formulations. For all different CDs, nanocapsules form was more effective as 
antiproliferative agent against lung and liver cancer cells. However, blank nanocapsules did not exert cytotoxic activity against healthy fibroblast cells (Figure 4) ruling out any intrinsic toxicity of the nanocapsules formulations.

The antitumoral activities of ERL in amphiphilic CD nanoparticle formulations were determined quantitatively in scaffold-based 3D multicellular spherical tumor model. The results are shown in Figures 7 . According to the results, cell viability after $48 \mathrm{~h}$ was $86 \%$ for HepG 2 spheroid and $81 \%$ for A549 spheroid in the cells treated with ERL solution alone. At the end of $72 \mathrm{~h}$, these values were evolved to $80 \%$ and $61 \%$ respectively. When the results are evaluated in terms of antitumoral activity of amphiphilic CD nanoparticles, it can be said that PC $\beta C D C 6$ nanocapsule is the most effective formulation at both time points. Cell viability for the PC $\beta C D C 6$ nanocapsule was $43 \%$ for HepG 2 spheroid and $46 \%$ for A549 spheroid after 72 h. The other most effective formulation is the 6 OCapro $\beta \mathrm{CD}$ nanocapsule with $62 \%$ cell viability for HepG2 spheroids and the PC $\beta$ CDC6 nanoparticle formulation with $46 \%$ cell viability for A549 spheroids.

\section{Tumoral Penetration Properties of Amphiphilic CD Nanoparticles on 3D Tumor Model}

Nanoparticles are expected to accumulate at tumor site as a result of the EPR effect and reduce tumor size by releasing the anticancer drug within the tumor site acting as drug reservoir facilitating drug diffusion or by internalization by the cancer cell via endocytosis. However, the tumor structure is highly dense and complicated with cancer cells as well as fibroblast cells. Therefore, the nanoparticle should also be able to penetrate into the deeper levels of this complex structure. In order to determine the tumor penetration capability of drug loaded CD nanospheres and nanocapsules with different surface charges and molecular structures in 3D spherical tumor model, Nile 
red was loaded as a fluorescent marker to the nanoparticles. The 3-dimensional tumor model was prepared with HepG2 and A549 cells using the Matrigel ${ }^{\circledR}$ assisted cell culture method. Images obtained by fluorescence microscopy are shown in Figure 8.

According to these microscope images, the presence of tumor penetration of all three CD derivatives was observed. When the luminous intensity of fluorescence dye is examined microscopically in NR- loaded nanoparticle formulations, it can be said that the cellular uptake of nanocapsules is higher than the nanosphere formulations in both cell lines. In particular, it has been observed qualitatively that polycationic PC $\beta C D C 6$ nanoparticles reach the depth of the tumor structure.

\section{DISCUSSION}

ERL, one of the first-generation tyrosine kinase inhibitors, is used in EGFR positive lung cancer and advanced metastatic prostate cancer. ERL has serious side effects in the clinic due to its low water solubility and oral bioavailability. In order to overcome these side effects, alternative formulation development studies have been carried out to increase the effectiveness of ERL. For example, Vaidya et al prepared cyclodextrinmodified ERL-loaded PLGA nanoparticles for NSCLC treatment. It was observed that CD-ERL complex loaded into PLGA nanoparticles increase apoptosis in 2D cell cultures and enhanced antitumoral efficiency in 3D cell cultures compared to free ERL solution [13]. In another study, it was demonstrated by in vivo studies that galactosylated ERL liposomes increase circulation time and relative bioavailability of ERL [15]. In another study, it was reported that ERL-loaded albumin nanoparticles increase the effectiveness of the drug in pancreatic cancer cells [46]. In this study, three different amphiphilic CD derivatives (6OCapro $\alpha \mathrm{CD}$, 6OCapro $\beta C D$ and PC $\beta C D C 6)$ with different physicochemical properties were synthesized and used to prepare nanoparticulate drug delivery systems in the form of nanospheres and nanocapsules. 
The efficacy of amphiphilic CD nanoparticulate systems prepared for ERL was evaluated in lung and liver cells.

\section{In vitro Characterization of Blank and Erlotinib Loaded Amphiphilic Cyclodextrin Nanoparticles}

Amphiphilic CDs are highly remarkable cyclic oligosaccharides grafted with aliphatic chains to obtain spontaneous self-assembling into (quasi)spherical nanometric particles in aqueous environment, suitable for the preparation of colloidal drug delivery systems [18,47-52]. Due to their various advantages such as spontaneous nanoparticle formation without any surfactants, increased loading efficiency and increased interaction with biological membranes, amphiphilic CD nanoparticles have been the interest of several research groups [18]. Amphiphilic CDs, obtained by taking advantage of facialselective chemical functionalization schemes to install aliphatic chains at either the primary or secondary rims of native CDs, have been used in the literature to prepare self-assembling nanocarrier system for a wide variety of APIs [18,47-52].

Blank or ERL-loaded amphiphilic CD nanoparticles were prepared with nanoprecipitation method without any surfactant and co-solvent needed and characterized in terms of particle size, PDI and zeta potential. According to the results shown in Table 1, all formulations have particle size smaller than $300 \mathrm{~nm}$ suggesting a possible benefit from the EPR effect. Mean particle size range of ERL-loaded nanospheres was between 88 and $186 \mathrm{~nm}$, and this range for corresponding nanocapsule formulations varied between 152-269 nm. Nanocapsules are known to have a larger particle size than nanospheres due to the oil core present in their structures. Nanospheres are defined as matrix type, solid, colloidal nanoparticles, while nanocapsules are vesicular systems consisting of an oily core surrounded by a 
polymeric membrane. The hydrophobic active ingredient is usually dissolved in the oily core of nanocapsules. This oily core and vesicular structure causes an increase in the particle sizes of nanocapsules compared to nanospheres [53-55].

Particle size distribution of nanoparticles plays an important role in nanoparticle-entrapped drug delivery, targeting, blood circulating half-life, cellular uptake and tumoral penetration properties of carrier systems. It is reported that nanoparticles having particle sizes above $300 \mathrm{~nm}$ activate the complement system and are removed from the blood in a short time and accumulate in the liver and spleen [56]. On the other hand, irregular and complicated vascularization of tumor tissue allows passive targeting of nanoparticles. Nanoparticulate systems can reach the cancerous tissue from the circulatory system by taking advantage of the "EPR effect" [57]. The main feature of EPR physiology is that the leaky vascular structure allows particles such as proteins, macromolecules, liposomes and micelles to pass into the cell [58]. When the tumor tissue reaches a certain size, the original vessels are insufficient to provide the necessary oxygen and nutrients. As a result, cancer cells begin to die from the necrotic nucleus, leading to the secretion of growth factors that trigger angiogenesis in tumor tissue. In the tumor tissue, new capillaries are created from the surrounding capillaries. The newly formed blood vessels contain spaces called fenestra between the endothelial cells, and the length of these fenestrae varies between $200-800 \mathrm{~nm}$ depending on the tumor type. Nanoparticles in the circulatory system can also reach the tumor tissue by leaking through these openings between the endothelial cells, depending on their size usually smaller than $400 \mathrm{~nm}[57,59]$. When ERL-loaded nanoparticles are evaluated in the light of this knowledge, it can be said that all amphiphilic CD derivatives are suitable for preparing a potential nanoparticulate system to benefit from passive targeting for ERL. 
According to the zeta potential values shown in Table 1,6OCaproaCD and 6OCapro $\beta C D$ nanoparticles are negatively charged in aqueous media. Conversely, PC $\beta C D C 6$ nanoparticles exhibit a heavy positive charge in ultrapure water. Amphiphilic 6OCapro $\alpha \mathrm{CD}$ and 6OCapro $\beta \mathrm{CD}$ are neutral because they do not contain charged groups. However, nanoparticle formulations prepared from these two derivatives are negatively charged. Zeta potential plays an important role in nanoparticle aggregation and stability as well as interaction with biological membranes, cellular uptake and opsonization in the bloodstream. Cationic nanoparticles can interact with cell membrane strongly owing to anionic molecules like proteoglycan, cholesterol and phospholipid of cell membranes compared to anionic nanoparticles [60]. Also, cationic nanoparticles have increased membrane surface tension and this results in pore formation on cell membrane $[61,62]$. Moreover, surface charge is effective in electrostatic attraction and/or improved vesicle enterocyte interactions as well as enhanced nanoparticle absorption from gastrointestinal barrier [63]. In addition, cationic nanoparticles are bound to the serum proteins especially after intravenous administration and removed by the mononuclear phagocytic system cells more rapidly. Therefore, the surface charge of nanoparticles should be designed in accordance with the potential route of application and target organ. In this study, ERL-loaded anionic 6OCaproaCD and 6OCapro $\beta C D$ nanoparticles appear to be more suitable for intravenous administration. Besides, this study aimed to increase the effectiveness of ERL in lung and liver cancer. Considering the rapid access and accumulation of cationic charged nanoparticles to these two organs, it may also be advantageous to use PC $\beta$ CDC6 nanoparticles as the ERL carrier nanoparticulate system.

\section{Encapsulation Efficiency of Amphiphilic CD Nanoparticles}

The ERL loading efficiencies of 6OCaproßCD nanospheres and nanocapsules are the 
lowest among the derivatives calculated as $49 \%$ and 59\%, respectively. However, for 6OCaproaCD, ERL loading values increased to $79 \%$ in nanospheres and $80 \%$ in nanocapsules. Overall, drug loading capacity for the polycationic PC $\beta C D C 6$, were $82 \%$ and $87 \%$, respectively for nanospheres and nanocapsules slightly higher than the alpha CD based nanoparticles. In previous studies of our group with amphiphilic CD nanoparticles as anticancer drug delivery systems, 6OCapro $\beta C D$ and $\mathrm{PC} \beta \mathrm{CDC} 6$ derivatives were used in the preparation of nanocarriers for different lipophilic drugs and the loading efficiency for both nanospheres and nanocapsules was found to be above $40 \%$ for anticancer drugs paclitaxel and camptothecin $[19,30]$. The higher loading capacity for ERL could result from its m-acetyleneaniline section to be far more hydrophobic and more prone to insert into CD cavity. Loading efficiency of CD nanoparticles are largely affected by the affinity of the drug to the CD cavity [64]. It is known that the surface charge of nanoparticles is a determinant parameter for drug loading efficiency as well as biodistribution [65]. In the literature, positively charged polymeric nanoparticles have been reported to have higher drug loading efficacy compared to negatively charged nanoparticles [63]. When the results obtained in the light of this information are evaluated, it is thought that the surface charge plays a role in the highest encapsulation efficiency of PC $\beta C D C 6$ nanoparticles.

\section{Short-Term Physical Stability of ERL-loaded Amphiphilic CD Nanoparticles}

Stability is an important parameter necessary to maintain quality, efficacy and safety pharmaceutical products and consists of physical, chemical, microbiological integrity valid both for the drug and the nanoparticle [66]. In this study, the physical stability of ERL-loaded nanospheres and nanocapsules was evaluated at $+4^{\circ} \mathrm{C}$ for 30 days in aqueous dispersion. There were no significant changes observed in particle size distribution, polydispersity index and zeta potential values for 30 days $(p>0.05)$. 
Previous studies with amphiphilic CD derivatives and various active molecules have shown that the prepared nanosystems are stable [19,37,67-69]. CDs may enhance stability by reforming physicochemical and thermodynamic properties of drug because drug was partially or totally surrounded with CDs cavity [70].

\section{Drug Release Studies}

As with conventional drug dosage forms, in vitro release tests are an important analytical tool for nanoparticle formulation development. The drug release profile of the prepared formulation provides very important information about the reliability, effectiveness, and behavior of the dosage form. Generally, it is expected that, the active ingredient released from nanoparticulate drug delivery systems after reaching the targeted tissues by passive or active targeting. Drug release studies are important both for the pharmacokinetic properties of nanoparticles and for determining in vivo efficacy, stability and clearance rate $[71,72]$. According to results of drug release study, it can be said that ERL is released more slowly from PC $\beta C D C 6$ nanocapsules than from any other formulation $(\mathrm{p}<0.05)$. The rate of release between other formulations did not statistically differ. In general terms, the nanocapsules exhibited slower release profiles than nanospheres in all derivatives in first hour; especially in the case of the polycationic derivative. In drug release mechanisms, it is known that the drug adsorbed onto the surface of nanoparticles is released first, and then drug dissolved or entrapped in the nanoparticle matrix is released [72]. In addition, ERL solubility, surface charge and physical stability of nanoparticles in release medium are important factors affecting drug release. Clearly, the drug released rapidly within the first 30 minutes is attributed to the drug adsorbed to the surface. In addition, in all CD derivatives, the amount of ERL released from nanocapsules is greater than that released from nanospheres. The main reason for this is that nanocapsules have more loading efficiency for ERL than 
nanospheres. Indeed, nanocapsules are known to have high drug loading capacity for lipophilic drugs due to the oil core [73]. As with other drugs, one reason for using CD in the formulation for ERL is to change the release profile of drug. For example, Vaidya et al. prepared ERL:Sulfobutylether- $\beta C D$ inclusion complex loaded PLGA nanoparticles and obtained an ERL release profile that lasted about 5 days with this formulation [13].

\section{Determination of Safety of Blank Amphiphilic CD Nanoparticles}

In order to determine the safety of blank amphiphilic CD nanoparticles, proliferation assay was performed on healthy L929 mouse fibroblast cells with WST-1 assay. As noted in the regulation, the study was completed in $24 \mathrm{~h}$ after adding the formulations. The results are given in Figure 4 and show that the nanoparticles have dose-dependent antiproliferative effect in L929 cells. In the study where three different concentrations were tested, it was determined that even at the highest NP doses (1/8 v:v), cell viability was above 70\%. According to ISO 10993-5, (2009), the minimum acceptable limit for biocompatibility is $70 \%$ cell viability [74]. Besides, in our previous studies, it was shown that 6OCaproBCD and PC BCDC6 have no toxic effect against both L929 and healthy bladder cell line (G/G) [39].

\section{Determination of IC 50 of ERL solution and ERL-loaded Nanoparticles on A549 and HepG2 cell lines}

$\mathrm{IC}_{50}$ value of ERL-loaded amphiphilic CD nanoparticles on lung and hepatocellular carcinoma cell line was determined. According to the results given in Table 2, at the end of the 48-hour, all nanoparticle formulations caused a significant decrease in the $\mathrm{IC}_{50}$ value of ERL in both cell lines. This means that anticancer efficacy can be achieved by using a smaller amount of ERL. One of the most important advantages of using nanoparticulate systems in chemotherapy compared to conventional chemotherapy is to 
provide successful treatment with less active molecule. In this way, the side effect of the drug can be reduced or eliminated. Increasing its effectiveness with nanoparticles is very important for ERL, whose clinical success has been proven but desired success cannot be achieved due to its side effects. Moreover, it is possible to prevent the drug resistance in cancer with reduced $\mathrm{IC}_{50}$ values because resistance is inevitable as a result of repeated exposure to chemotherapy. In this context, the amphiphilic CD nanoparticles have the potential to be the appropriate nanoparticulate system for efficient and safe ERL chemotherapy.

\section{Anticancer Efficacy of Blank and ERL-loaded Amphiphilic CD Nanoparticles}

The anticancer efficacy of ERL-loaded amphiphilic CD nanoparticles was compared to the drug in solution against lung and liver cancer cells. The results suggest that encapsulated ERL formulations provide increased anticancer activity compared to free ERL solution $(\mathrm{p}<0.05)$. Furthermore, all nanoparticle formulations caused a significant decrease in cell viability in both types of cancer cells compared to untreated control group ( $\mathrm{p}<0.05$ ). According to the results, blank amphiphilic 6OCaproaCD and PC $\beta$ CDC6 nanocapsule formulations caused increased cell death in HepG2 cells than the conventional ERL solution. In A549 cells, blank 6OCaproßCD nanosphere and blank PC $\beta C D C 6$ nanocapsule were found to be more effective than the free drug. In general, A549 cells were observed to be more sensitive and nanoparticles showed more anticancer activity in these cells. The main reason for this is thought to be doubling times of the cells. A549 cell doubling time is $22 \mathrm{~h}$ and the HepG2 cell doubling time is $48 \mathrm{~h}$. As untreated cells are used as control groups in assays, it is an expected result that A549 cells with shorter doubling time will be more sensitive after $48 \mathrm{~h}$ incubation period with nanoparticles. These results show that the effectiveness of ERL can be 
increased in both liver and lung cells with amphiphilic CD nanoparticles.

\section{Cholesterol Depletion Ability of Amphiphilic Cyclodextrin Nanoparticles}

Amphiphilic CD nanoparticles were also evaluated in cell culture for their ability to deplete cholesterol. According to results of cholesterol assay, all amphiphilic cyclodextrin derivatives depleted cholesterol in HepG2 and A549 cell lines when compared to untreated control group. Besides, methyl- $\beta$ CD treated cells were used as positive control group in cholesterol assay. The ability of the methyl- $\beta \mathrm{CD}$ to remove cholesterol from the cell membrane is known in the literature. It has been determined that PC $\beta$ CDC6 nanosphere and nanocapsule formulations in HepG2 cells and 6OCaproßCD nanosphere and nanocapsules in A549 cells are capable of extract almost equal cholesterol with methyl- $\beta C D$. It was observed that amphiphilic CD nanocapsules tend to remove more cholesterol from nanospheres, but this difference is not significant except for the amphiphilic 6OCaproaCD derivative. It can also be said that the cholesterol amount of cells incubated with beta-derived CD nanoparticles is lower than that of cells incubated with the alpha-derived CD nanoparticles. When evaluated together with the data given in Figure 5, it is thought that the nanoparticles showing higher anticancer activity in A549 cells may be attributed to the amount of cellular cholesterol. Amphiphilic CD derivatives exhibited synergistic effects on cancer cells due to their cholesterol affinities, and this activity was more pronounced on A549 cells with higher cholesterol levels.

It was shown in our previous study that $6 \mathrm{OCapro} \beta \mathrm{CD}$ and $\mathrm{PC} \beta \mathrm{CDC} 6$ triggered apoptosis by removing cholesterol from the membrane in human breast cancer MCF-7 cells [39]. Similar findings have been reported to other CD derivatives, such as methylated- $\beta C D$, to improve drug uptake and overcome drug resistance for anticancer or anti-infective drugs through cell membrane cholesterol depletion $[75,76]$. In this 
paper, this effect of amphiphilic CD nanoparticles has been shown against liver and lung cells. This intrinsic apoptotic activity of the anionic and cationic nanoparticles is an important parameter that may contribute to the anticancer efficacy of nanomedicines for anticancer activity.

Cholesterol depletion ability of the CD nanocarriers are seen as an indicative of selective apoptotic effect on cancer cells and can be used a means to overcome drug resistance caused by cancer cell membranes that have more abundant cholesterol domains leading to cell membrane rigidity and drug resistance. As previously emphasized, one of the most important obstacles to ERL's clinical success is drug resistance. It is known that more than half of the patients develop resistance approximately 1 year after starting ERL treatment [77,78]. In addition, Chen et al. showed that the level of cellular cholesterol in the gefitinib (EGFR inhibitor) resistant lung cancer cell lines was significantly higher than that the gefitinib sensitive cell line and they also showed that a decrease in cellular cholesterol increases the sensitivity of gefitinib [79]. Besides, it is known that the cholesterol-rich cell membrane regulates the function of Multidrug Resistance P-Glycoprotein (P-gp). Moreover, it has also been shown to cause P-gp inhibition in NIH 3T3 MDR1 cells by decreasing cholesterol with heptakis (2,6-di-O-methyl) $\beta$-CD [80]. Erlotinib is also a P-gp substrate [81] and, thanks to its formulation with amphiphilic CD nanoparticles, increased efficacy can be achieved by P-gp inhibition by depleted cellular cholesterol. In line with the surface charge property, cholesterol depletion characteristics of the amphiphilic CD nanoparticles also affect anticancer efficacy of ERL and overcoming drug resistance in cancer cells. 


\section{Antitumoral Activity of ERL-loaded Amphiphilic CD Nanoparticles on 3D Spheroid Method}

The in vitro 3D tumor spheroid model is a bridge that fills the gap between 2D cell culture and in vivo trials. Tumorigenesis is a biological process controlled by extracellular matrix (ECM), cancer cell, and stroma. In this biological process, the development and metastasis of cancer cells depend on many factors, such as growth factors, hormones, and other cells within the ECM [33]. These spherical tumors formed in vitro can be considered as small microtumors because they are self-assembling cancer structures formed in a hierarchical arrangement where intercellular contacts form a $3 \mathrm{D}$ spherical structure $[32,34]$. Cell-based assays are the main tool for assessing the potential efficacy of a new compound in drug discovery. In order to obtain the most reliable results, the cell culture model used as the test platform should work similarly to the cells in vivo. Cellular responses to drug therapies in 3D cell culture models have been shown to be closer to the in vivo findings compared to $2 \mathrm{D}$ culture [82].

The antitumoral efficacy of ERL-loaded amphiphilic CD nanoparticles in 3D tumors prepared from HepG2 or A549 cells were found to be significantly different from conventional cell culture results. At the end of both 48 and $72 \mathrm{~h}$, the antitumoral activity of ERL-loaded nanoparticles on 3D tumors was less than that of 2D cell culture as can be expected $(\mathrm{p}<0.05)$. However, the results showed that all the formulations had stronger antitumoral activity than the drug solution after $72 \mathrm{~h}$. Cells in $3 \mathrm{D}$ multicellular spherical tumors are typically known to have lower sensitivity to cytotoxic drugs than in $2 \mathrm{D}$ culture. It is argued that this difference has various reasons such as decreased drug penetration, development of hypoxic nucleus and decreased cell growth [83]. It is also known that increased intracellular signaling by enhancing cell-cell interaction in 3D cell culture is an important factor in explaining the decreased drug sensitivity in spherical tumors. Conventional 2D cell culture data are somewhat limited as these studies do not 
represent anatomic and physiologic condition of cells in live tissues [84]. 3D in vitro tumor models are accepted as crossover complementing shortfalls between 2D cell cultures and in vivo animal models [34].

\section{Tumoral Penetration Properties of Amphiphilic CD Nanoparticles on 3D}

\section{Tumor Model}

According to the antitumoral penetration results of nanoparticles determined in 3D spherical tumor model, it was observed that all nanoparticles prepared from three different amphiphilic CD derivatives loaded with Nile Red were able to penetrate the multilayer tumor. Furthermore, penetration levels of different CD nanoparticles were determined qualitatively by fluorescence microscopy. When the luminous intensity of fluorescent dye is examined microscopically, it can be said that the penetration of nanocapsule formulations for all $\mathrm{CD}$ derivatives is higher than the nanosphere analogues. One of the reasons for this result can be attributed to the nanocapsules oil core [85] that results in a higher liquid content for the delivery system and decreases stiffness of the polymer membrane surrounding the core. We believe that this may have facilitated the intercellular passage of the nanocapsules within the $3 \mathrm{D}$ tumor model that is a dense and complicated structure. This finding is also in accordance with the 2D cell culture studies in which nanocapsule formulations for each $\mathrm{CD}$ resulted in higher cytotoxicity based probably on the higher cellular uptake of the nanocapsule-bound ERL.

Figure 8 considered together with anticancer efficacy data reveal that PC $\beta C D C 6$ nanocapsules were the most effective formulation in terms of anticancer efficacy and tumoral penetration for both lung and liver cancer models. As expected, positive surface charges of nanoparticles increase tumoral penetration. The positively charged nanoparticles form more rapid and strong interactions with negatively charged 
components such as sialic acid, cholesterol and phospholipids in the membrane structure of the cells when compared to anionic nanoparticles of the same polymer family $[86,87]$. In the literature, it was reported that the surface charge of nanoparticles increases the cellular interaction. By considering electrostatic interactions between nanoparticles and negatively charged pores of the vessel wall, a mathematical model was developed for cationic gold nanoparticle delivery to glioblastoma tumors. It was emphasized that electrostatic attraction caused by cationic charges was shown to cause a two-fold increase in the transvascular passage of nanoparticles [88]. Moreover, cationic nanoparticles may cause more disruption of plasma-membrane integrity, stronger mitochondrial and lysosomal damage than negatively charged nanoparticles [89].

\section{Conclusion}

In conclusion, ERL-loaded amphiphilic CD nanospheres and nanocapsules were prepared and characterized in this study. It was determined that the amphiphilic CD nanoparticles are suitable carrier systems for ERL in terms of mean particle size, polydispersity index and stability. In addition, it has been shown that nanoparticles increase ERL's anticancer efficacy with the conventional and 3D tumor model made in lung and hepatocellular carcinoma cells. When the cholesterol depletion, tumoral penetration and antitumoral efficacy studies are evaluated together, it is considered important to investigate the potential of ERL bound to amphiphilic CD nanocarriers against drug resistant lung or liver cancers.

\section{Acknowledgements}

This study was financially supported by the Spanish Ministry of Science and Innovation, ref RTI2018-097609-B-C21. 
References

1. Ishii G, Ochiai A, Neri S. Phenotypic and functional heterogeneity of cancerassociated fibroblast within the tumor microenvironment. Adv Drug Deliv Rev. 2016;99(Pt B):186-196.

2. Tan S, Wang G. Redox-responsive and $\mathrm{pH}$-sensitive nanoparticles enhanced stability and anticancer ability of erlotinib to treat lung cancer in vivo. Drug Des Devel Ther. 2017;11:3519-3529.

3. Kim J, Ramasamy T, Choi JY, et al. PEGylated polypeptide lipid nanocapsules to enhance the anticancer efficacy of erlotinib in non-small cell lung cancer. Colloids Surf B Biointerfaces. 2017;150:393-401.

4. Cohen MH. FDA Drug Approval Summary: Erlotinib (Tarceva®) Tablets. The Oncologist. 2005;10:461-466.

5. Kelley RK, Ko AH. Erlotinib in the treatment of advanced pancreatic cancer. Biologics. 2008;2(1):83-95.

6. Vrignaud S, Hureaux J, Wack S, et al. Design, optimization and in vitro evaluation of reverse micelle-loaded lipid nanocarriers containing erlotinib hydrochloride. Int J Pharm. 2012;436(1-2):194-200.

7. van der Meel R, Sulheim E, Shi Y, et al. Smart cancer nanomedicine. Nat Nanotechnol. 2019;14(11):1007-1017.

8. Wolfram J, Ferrari M. Clinical Cancer Nanomedicine. Nano Today. 2019;25:8598.

9. Li H, Qiu H, Wang J, et al. Erlotinib-silk fibroin nanoparticles in inhibiting tumor. Polymer Bulletin. 2020; 77:4325-4334.

10. Nottingham E, Sekar V, Mondal A, et al. The Role of Self-Nanoemulsifying Drug Delivery Systems of CDODA-Me in Sensitizing Erlotinib-Resistant NonSmall Cell Lung Cancer. J Pharm Sci. 2020;109(6):1867-1882.

11. Pandey P, Dua K, Dureja H. Erlotinib loaded chitosan nanoparticles:

Formulation, physicochemical characterization and cytotoxic potential. Int $\mathrm{J}$ Biol Macromol. 2019;139:1304-1316.

12. Truong DH, Le VKH, Pham TT, et al. Delivery of erlotinib for enhanced cancer treatment: An update review on particulate systems. Journal of Drug Delivery Science and Technology. 2020;55:101348.

13. Vaidya B, Parvathaneni V, Kulkarni NS, et al. Cyclodextrin modified erlotinib loaded PLGA nanoparticles for improved therapeutic efficacy against non-small cell lung cancer. Int J Biol Macromol. 2019;122:338-347.

14. Shen Y, Li W. HA/HSA co-modified erlotinib-albumin nanoparticles for lung cancer treatment. Drug Des Devel Ther. 2018;12:2285-2292. 
15. $\mathrm{Xu} \mathrm{H}, \mathrm{He} \mathrm{C}$, Liu Y, et al. Novel therapeutic modalities and drug delivery erlotinib liposomes modified with galactosylated lipid: in vitro and in vivo investigations. Artif Cells Nanomed Biotechnol. 2018;46(8):1902-1907.

16. Crini G. Review: a history of cyclodextrins. Chem Rev. 2014;114(21):10940-75.

17. Jansook P, Ogawa N, Loftsson T. Cyclodextrins: structure, physicochemical properties and pharmaceutical applications. Int J Pharm. 2018;535(1-2):272-284.

18. Bilensoy E, Hincal AA. Recent advances and future directions in amphiphilic cyclodextrin nanoparticles. Expert Opin Drug Deliv. 2009;6(11):1161-73.

19. Varan G, Benito JM, Mellet CO, et al. Development of polycationic amphiphilic cyclodextrin nanoparticles for anticancer drug delivery. Beilstein J Nanotechnol. 2017;8:1457-1468.

20. Bilensoy E, Doğan L, Şen M, et al. Complexation behavior of antiestrogen drug tamoxifen citrate with natural and modified $\beta$-cyclodextrins. Journal of Inclusion Phenomena and Macrocyclic Chemistry. 2007;57(1-4):651-655.

21. Bilensoy E, Gurkaynak O, Dogan AL, et al. Safety and efficacy of amphiphilic beta-cyclodextrin nanoparticles for paclitaxel delivery. Int J Pharm. 2008;347(12):163-70.

22. Bilensoy E, Gurkaynak O, Ertan M, et al. Development of nonsurfactant cyclodextrin nanoparticles loaded with anticancer drug paclitaxel. J Pharm Sci. 2008;97(4):1519-29.

23. Bondi ML, Scala A, Sortino G, et al. Nanoassemblies Based on Supramolecular Complexes of Nonionic Amphiphilic Cyclodextrin and Sorafenib as Effective Weapons to Kill Human HCC Cells. Biomacromolecules. 2015 Dec 14;16(12):3784-91.

24. Bonnet V, Gervaise C, Djedaini-Pilard F, et al. Cyclodextrin nanoassemblies: a promising tool for drug delivery. Drug Discov Today. 2015;20(9):1120-6.

25. Cavalli R, Donalisio M, Civra A, et al. Enhanced antiviral activity of Acyclovir loaded into beta-cyclodextrin-poly(4-acryloylmorpholine) conjugate nanoparticles. J Control Release. 2009;137(2):116-22.

26. Conte C, Scala A, Siracusano G, et al. Nanoassemblies based on non-ionic amphiphilic cyclodextrin hosting Zn(II)-phthalocyanine and docetaxel: Design, physicochemical properties and intracellular effects. Colloids Surf B Biointerfaces. 2016;146:590-7.

27. Erdogar N, Esendagli G, Nielsen TT, et al. Therapeutic efficacy of folate receptor-targeted amphiphilic cyclodextrin nanoparticles as a novel vehicle for paclitaxel delivery in breast cancer. Journal of drug targeting. 2018;26(1):66-74.

28. Jiménez Blanco JL, Benito JM, Ortiz Mellet C, et al. Molecular nanoparticlebased gene delivery systems. Journal of Drug Delivery Science and Technology. 2017;42:18-37. 
29. Rouf MA, Bilensoy E, Vural İ, et al. Inclusion complexation of rapamycin with beta-cyclodextrin to improve solubility and stability of the drug. European Journal of Pharmaceutical Sciences. 2007;32(1):S46-S47.

30. Ünal H, d'Angelo I, Pagano E, et al. Core-shell hybrid nanocapsules for oral delivery of camptothecin: formulation development, in vitro and in vivo evaluation. Journal of Nanoparticle Research. 2015;17(1).

31. Unal H, Ozturk N, Bilensoy E. Formulation development, stability and anticancer efficacy of core-shell cyclodextrin nanocapsules for oral chemotherapy with camptothecin. Beilstein J Org Chem. 2015;11:204-12.

32. Varan G, Patrulea V, Borchard G, et al. Cellular Interaction and Tumoral Penetration Properties of Cyclodextrin Nanoparticles on 3D Breast Tumor Model. Nanomaterials (Basel, Switzerland). 2018;8(2).

33. Kim JB. Three-dimensional tissue culture models in cancer biology. Semin Cancer Biol. 2005 Oct;15(5):365-77.

34. da Rocha EL, Porto LM, Rambo CR. Nanotechnology meets 3D in vitro models: tissue engineered tumors and cancer therapies. Mater Sci Eng C Mater Biol Appl. 2014;34:270-9.

35. Chimento A, Casaburi I, Avena P, et al. Cholesterol and Its Metabolites in Tumor Growth: Therapeutic Potential of Statins in Cancer Treatment. Front Endocrinol (Lausanne). 2018;9:807.

36. Huang B, Song B-1, Xu C. Cholesterol metabolism in cancer: mechanisms and therapeutic opportunities. Nature Metabolism. 2020;2(2):132-141.

37. Unal S, Aktas Y, Benito JM, et al. Cyclodextrin nanoparticle bound oral camptothecin for colorectal cancer: Formulation development and optimization. Int J Pharm. 2020;584:119468.

38. Diaz-Moscoso A, Balbuena P, Gomez-Garcia M, et al. Rational design of cationic cyclooligosaccharides as efficient gene delivery systems. Chem Commun. 2008;2001-2003.

39. Varan G, Oncul S, Ercan A, et al. Cholesterol-Targeted Anticancer and Apoptotic Effects of Anionic and Polycationic Amphiphilic Cyclodextrin Nanoparticles. J Pharm Sci. 2016;105(10):3172-3182.

40. Dora CP, Trotta F, Kushwah V, et al. Potential of erlotinib cyclodextrin nanosponge complex to enhance solubility, dissolution rate, in vitro cytotoxicity and oral bioavailability. Carbohydr Polym. 2016;137:339-349.

41. Ghanta P, Bhatnagar U, Pasumarthi S, et al. Cytotoxic Evaluation Using Murine Fibroblasts (L-929) Three Dimensional Cell Culture Technique. Journal of Pharmacology and Toxicology. 2019;14(1):18-27. 
42. Babic A, Herceg V, Ateb I, et al. Tunable phosphatase-sensitive stable prodrugs of 5-aminolevulinic acid for tumor fluorescence photodetection. J Control Release. 2016;235:155-164.

43. Alejandro M-A, Marta G-G, Annabelle G, et al. Monodisperse Nanoparticles from Self-Assembling Amphiphilic Cyclodextrins: Modulable Tools for the Encapsulation and Controlled Release of Pharmaceuticals. Medicinal Chemistry. 2012;8(4):524-532.

44. Deng S, Gigliobianco MR, Censi R, et al. Polymeric Nanocapsules as Nanotechnological Alternative for Drug Delivery System: Current Status, Challenges and Opportunities. Nanomaterials (Basel, Switzerland). 2020;10(5).

45. Erdogar N, Akkin S, Bilensoy E. Nanocapsules for Drug Delivery: An Updated Review of the Last Decade. Recent Pat Drug Deliv Formul. 2018;12(4):252-266.

46. Noorani M, Azarpira N, Karimian K, et al. Erlotinib-loaded albumin nanoparticles: A novel injectable form of erlotinib and its in vivo efficacy against pancreatic adenocarcinoma ASPC-1 and PANC-1 cell lines. Int J Pharm. 2017;531(1):299-305.

47. Varan G, Varan C, Erdoğar N, et al. Amphiphilic cyclodextrin nanoparticles. International Journal of Pharmaceutics. 2017;531(2):457-469.

48. Erdogar N, Varan G, Bilensoy E. Amphiphilic Cyclodextrin Derivatives for Targeted Drug Delivery to Tumors. Curr Top Med Chem. 2017;17(13):15211528.

49. Zagami R, Rapozzi V, Piperno A, et al. Folate-Decorated Amphiphilic Cyclodextrins as Cell-Targeted Nanophototherapeutics. Biomacromolecules. 2019;20(7):2530-2544.

50. Pflueger I, Charrat C, Mellet CO, et al. Cyclodextrin-based facial amphiphiles: assessing the impact of the hydrophilic-lipophilic balance in the self-assembly, DNA complexation and gene delivery capabilities [10.1039/C6OB01882C]. Organic \& Biomolecular Chemistry. 2016;14(42):10037-10049.

51. Zhang J, Ma PX. Cyclodextrin-based supramolecular systems for drug delivery: recent progress and future perspective. Adv Drug Deliv Rev. 2013;65(9):121533.

52. Munoz J, Crivillers N, Ravoo BJ, et al. Cyclodextrin-based superparamagnetic host vesicles as ultrasensitive nanobiocarriers for electrosensing. Nanoscale. 2020;12(17):9884-9889.

53. Letchford K, Burt H. A review of the formation and classification of amphiphilic block copolymer nanoparticulate structures: micelles, nanospheres, nanocapsules and polymersomes. Eur J Pharm Biopharm. 2007;65(3):259-69.

54. Mora-Huertas CE, Fessi H, Elaissari A. Polymer-based nanocapsules for drug delivery. Int J Pharm. 2010;385(1-2):113-42. 
55. Paiva AM, Pinto RA, Teixeira M, et al. Development of noncytotoxic PLGA nanoparticles to improve the effect of a new inhibitor of p53-MDM2 interaction. Int J Pharm. 2013;454(1):394-402.

56. $\mathrm{He} \mathrm{C,} \mathrm{Hu} \mathrm{Y,} \mathrm{Yin} \mathrm{L,} \mathrm{et} \mathrm{al.} \mathrm{Effects} \mathrm{of} \mathrm{particle} \mathrm{size} \mathrm{and} \mathrm{surface} \mathrm{charge} \mathrm{on} \mathrm{cellular}$ uptake and biodistribution of polymeric nanoparticles. Biomaterials. 2010;31(13):3657-66.

57. Nichols JW, Bae YH. EPR: Evidence and fallacy. J Control Release. 2014;190:451-64.

58. Danhier F. To exploit the tumor microenvironment: Since the EPR effect fails in the clinic, what is the future of nanomedicine? J Control Release. 2016 Dec 28;244(Pt A):108-121.

59. Torchilin V. Tumor delivery of macromolecular drugs based on the EPR effect. Adv Drug Deliv Rev. 2011;63(3):131-5.

60. Verma A, Stellacci F. Effect of surface properties on nanoparticle-cell interactions. Small. 2010;6(1):12-21.

61. Behzadi S, Serpooshan V, Tao W, et al. Cellular uptake of nanoparticles: journey inside the cell. Chem Soc Rev. 2017;46(14):4218-4244.

62. Foroozandeh P, Aziz AA. Insight into Cellular Uptake and Intracellular Trafficking of Nanoparticles. Nanoscale Res Lett. 2018;13(1):339.

63. Velpula A, Jukanti R, Janga KY, et al. Proliposome powders for enhanced intestinal absorption and bioavailability of raloxifene hydrochloride: effect of surface charge. Drug Dev Ind Pharm. 2013;39(12):1895-906.

64. Gadade DD, Pekamwar SS. Cyclodextrin Based Nanoparticles for Drug Delivery and Theranostics. Adv Pharm Bull. 2020;10(2):166-183.

65. Reddy LHS, R. K.; Chuttani, K.; Mishra, A. K.; Murthy R. R. Etoposideincorporated Tripalmitin Nanoparticles With Different Surface Charge: Formulation, Characterization, Radiolabeling, and Biodistribution Studiesf. The AAPS Journal. 2004;6.

66. Makoni PA, Wa Kasongo K, Walker RB. Short Term Stability Testing of Efavirenz-Loaded Solid Lipid Nanoparticle (SLN) and Nanostructured Lipid Carrier (NLC) Dispersions. Pharmaceutics. 2019;11(8).

67. Evans JC, Malhotra M, Fitzgerald KA, et al. Formulation and Evaluation of Anisamide-Targeted Amphiphilic Cyclodextrin Nanoparticles To Promote Therapeutic Gene Silencing in a 3D Prostate Cancer Bone Metastases Model. Mol Pharm. 2017;14(1):42-52.

68. Geze A, Putaux JL, Choisnard L, et al. Long-term shelf stability of amphiphilic beta-cyclodextrin nanosphere suspensions monitored by dynamic light scattering and cryo-transmission electron microscopy. J Microencapsul. 2004;21(6):60713. 
69. Salih M, Omolo CA, Agrawal N, et al. Supramolecular amphiphiles of Betacyclodextrin and Oleylamine for enhancement of vancomycin delivery. Int $\mathbf{J}$ Pharm. 2020;574:118881.

70. Gidwani B, Vyas A. A Comprehensive Review on Cyclodextrin-Based Carriers for Delivery of Chemotherapeutic Cytotoxic Anticancer Drugs. Biomed Res Int. 2015;2015:198268.

71. Patra JK, Das G, Fraceto LF, et al. Nano based drug delivery systems: recent developments and future prospects. J Nanobiotechnology. 2018;16(1):71.

72. Wong PT, Choi SK. Mechanisms of drug release in nanotherapeutic delivery systems. Chem Rev. 2015;115(9):3388-432.

73. Talevi AGMERME. Applications of Nanosystems to Anticancer Drug Therapy (Part I. Nanogels, Nanospheres, Nanocapsules). Recent Patents on Anti-cancer Drug Discovery. 2014;9:83-98.

74. <ISO10993_5_2009.pdf $>$. Available from: http://www.dent.chula.ac.th/upload/images2/dent-biomaterial/cytotoxicitytest/ISO10993 5 2009.pdf

75. Grosse PY, Bressolle F, Pinguet F. In vitro modulation of doxorubicin and docetaxel antitumoral activity by methyl- $\beta$-cyclodextrin. European Journal of Cancer. 1998;34(1):168-174.

76. Mohammad N, Malvi P, Meena AS, et al. Cholesterol depletion by methyl-betacyclodextrin augments tamoxifen induced cell death by enhancing its uptake in melanoma. Molecular cancer. 2014;13:204.

77. Sequist LV, Waltman BA, Dias-Santagata D, et al. Genotypic and histological evolution of lung cancers acquiring resistance to EGFR inhibitors. Sci Transl Med. 2011;3(75):75ra26.

78. Tang J, Salama R, Gadgeel SM, et al. Erlotinib resistance in lung cancer: current progress and future perspectives. Front Pharmacol. 2013;4:15.

79. Chen Q, Pan Z, Zhao M, et al. High cholesterol in lipid rafts reduces the sensitivity to EGFR-TKI therapy in non-small cell lung cancer. J Cell Physiol. 2018;233(9):6722-6732.

80. Fenyvesi F, Fenyvesi E, Szente L, et al. P-glycoprotein inhibition by membrane cholesterol modulation. Eur J Pharm Sci. 2008;34(4-5):236-42.

81. de Vries NA, Buckle T, Zhao J, et al. Restricted brain penetration of the tyrosine kinase inhibitor erlotinib due to the drug transporters P-gp and BCRP. Invest New Drugs. 2012;30(2):443-9.

82. Thoma CR, Zimmermann M, Agarkova I, et al. 3D cell culture systems modeling tumor growth determinants in cancer target discovery. Adv Drug Deliv Rev. 2014;69-70:29-41. 
83. Hakanson M, Textor M, Charnley M. Engineered 3D environments to elucidate the effect of environmental parameters on drug response in cancer. Integr Biol (Camb). 2011;3(1):31-8.

84. Fennema E, Rivron N, Rouwkema J, et al. Spheroid culture as a tool for creating 3D complex tissues. Trends Biotechnol. 2013;31(2):108-15.

85. Valente I, del Valle LJ, Casas MT, et al. Nanospheres and nanocapsules of amphiphilic copolymers constituted by methoxypolyethylene glycol cyanoacrylate and hexadecyl cyanoacrylate units. Express Polymer Letters. 2013;7(1):2-20.

86. Bilensoy E, Sarisozen C, Esendagli G, et al. Intravesical cationic nanoparticles of chitosan and polycaprolactone for the delivery of Mitomycin $\mathrm{C}$ to bladder tumors. Int J Pharm. 2009;371(1-2):170-6.

87. Erdoğar N, Iskit AB, Eroğlu H, et al. Antitumor Efficacy of Bacillus CalmetteGuerin Loaded Cationic Nanoparticles for Intravesical Immunotherapy of Bladder Tumor Induced Rat Model. Journal of Nanoscience and Nanotechnology. 2015;15(12):10156-10164.

88. Stylianopoulos T, Soteriou K, Fukumura D, et al. Cationic nanoparticles have superior transvascular flux into solid tumors: insights from a mathematical model. Ann Biomed Eng. 2013;41(1):68-77.

89. Frohlich E. The role of surface charge in cellular uptake and cytotoxicity of medical nanoparticles. Int J Nanomedicine. 2012;7:5577-91. 
Table 1. Averaged hydrodynamic diameter $(\mathrm{nm})$, polydispersity index and zeta potential $(\mathrm{mV})$ measurement of blank and ERL-loaded amphiphilic CD nanospheres and nanocapsules ( $\mathrm{n}=3, \pm \mathrm{SD})$.

Table 2. $\mathrm{IC}_{50}$ values $(\mu \mathrm{M})$ of ERL solution and ERL-loaded nanoparticle formulations on cancer cell lines A549 (lung) and HepG2 (liver) for 24 and 48h ( $\mathrm{n}=3, \pm \mathrm{SD})\left({ }^{*} \mathrm{p}<\right.$ 0.05 compared with ERL solution).

Figure 1. ERL encapsulation efficiency in amphiphilic CD nanosphere and nanocapsule formulations $(\mathrm{n}=3, \pm \mathrm{SD}) * \mathrm{p}<0.05$.

Figure 2. Time dependent mean particle size, PDI (a) and zeta potential (b) of ERLloaded amphiphilic CD nanosphere and nanocapsule formulations $(\mathrm{n}=3 \pm \mathrm{SD})$

Figure 3. Cumulative release profile of ERL from different amphiphilic CD nanoparticles $(\mathrm{n}=3, \pm \mathrm{SD})$

Figure 4. Effect of different blank amphiphilic CD nanoparticles on the proliferation of healthy L929 mouse fibroblast cells $(n=4, \pm S D)$

Figure 5. Antiproliferative effect of blank and ERL-loaded amphiphilic CD nanospheres and nanocapsules against 2D HepG2 hepatocellular carcinoma cell line (a) and 2D A459 non-small cell lung cancer cell line (b) $\left(n=4 ; \pm\right.$ SD). ${ }^{*} p<0.05$ compared with ERL solution

Figure 6. Total cellular cholesterol amount of A549 and HepG2 cells treated with blank amphiphilic cyclodextrin nanoparticles in 24 hours $(\mathrm{n}=4 ; \pm \mathrm{SD})$.

Figure 7. Antitumor effect of ERL-loaded amphiphilic CD nanospheres and nanocapsules against 3D HepG2 (a) and A549 (b) cell line ( $=4 ; \pm$ SD). ${ }^{*} \mathrm{p}<0.05$ compared with ERL solution

Figure 8. Tumoral penetration of Nile red-loaded amphiphilic nanospheres and nanocapsules into 3D A549 and 3D HepG2 spherical tumors. 


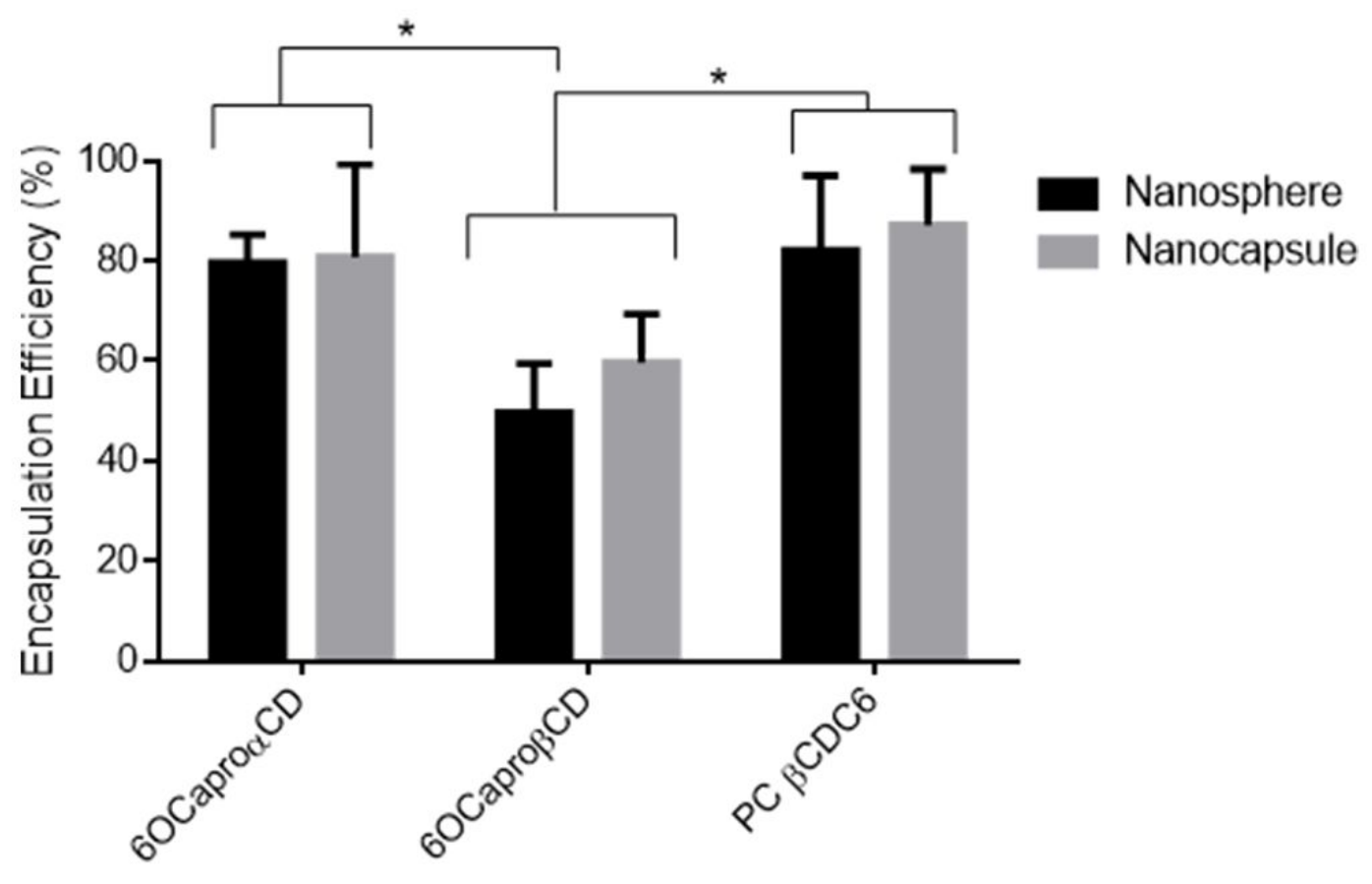

Figure 1. ERL encapsulation efficiency in amphiphilic CD nanosphere and nanocapsule formulations $(n=3$, $\pm S D) * p<0.05$. 
a
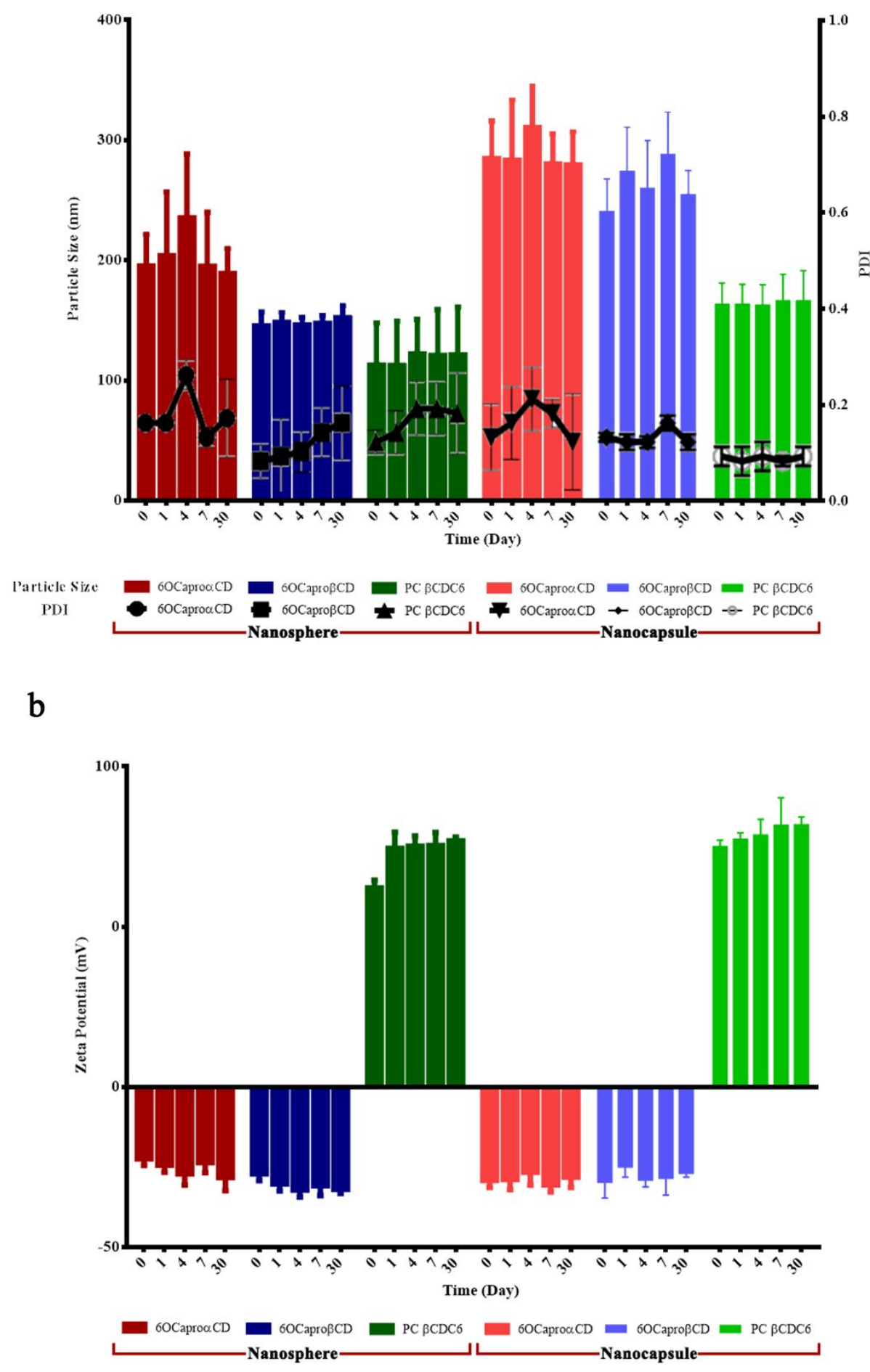

Figure 2. Time dependent mean particle size, PDI (a) and zeta potential (b) of ERL-loaded amphiphilic CD nanosphere and nanocapsule formulations $(n=3 \pm S D)$ 


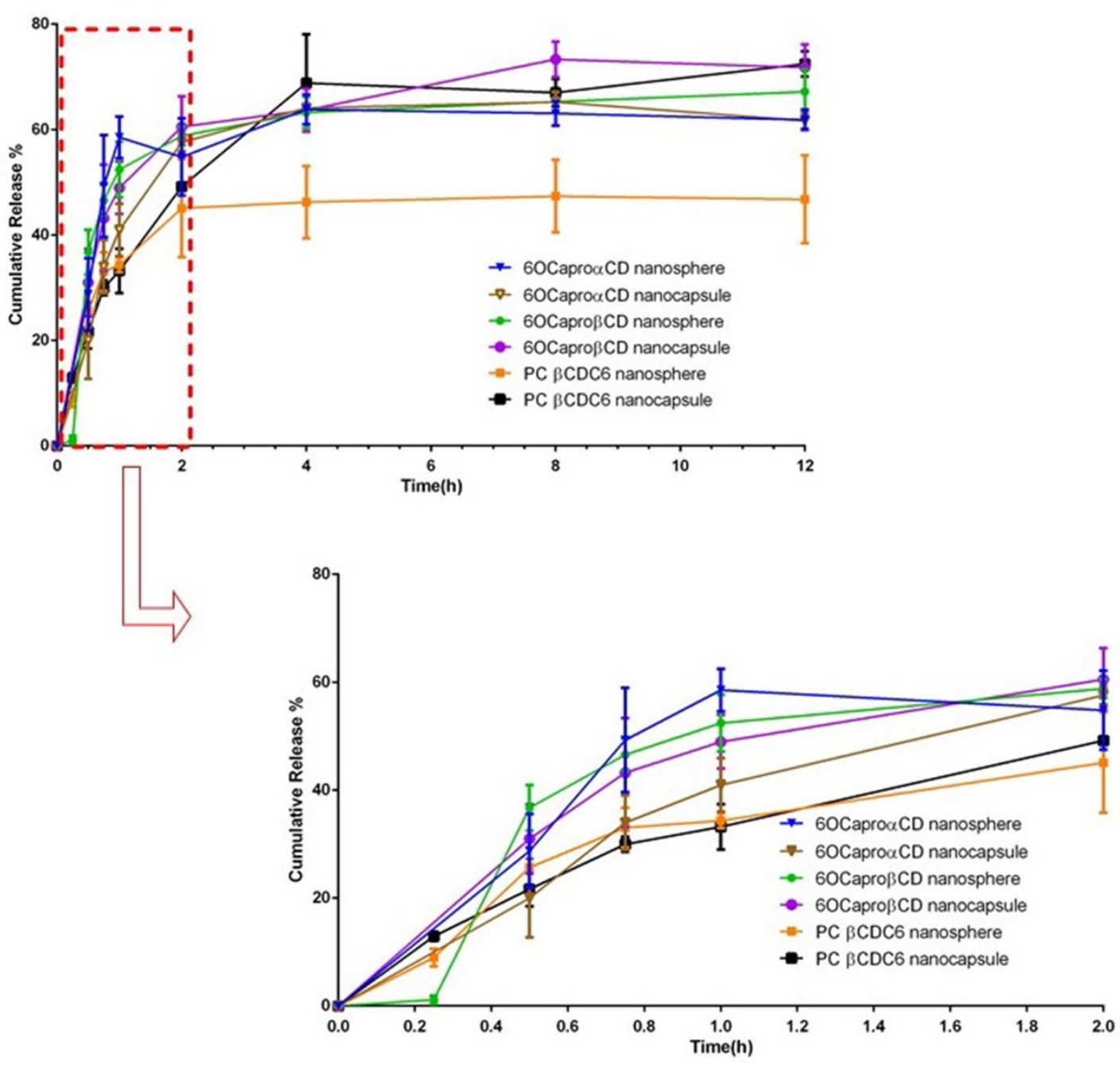

Figure 3. Cumulative release profile of ERL from different amphiphilic CD nanoparticles $(n=3, \pm S D)$ 


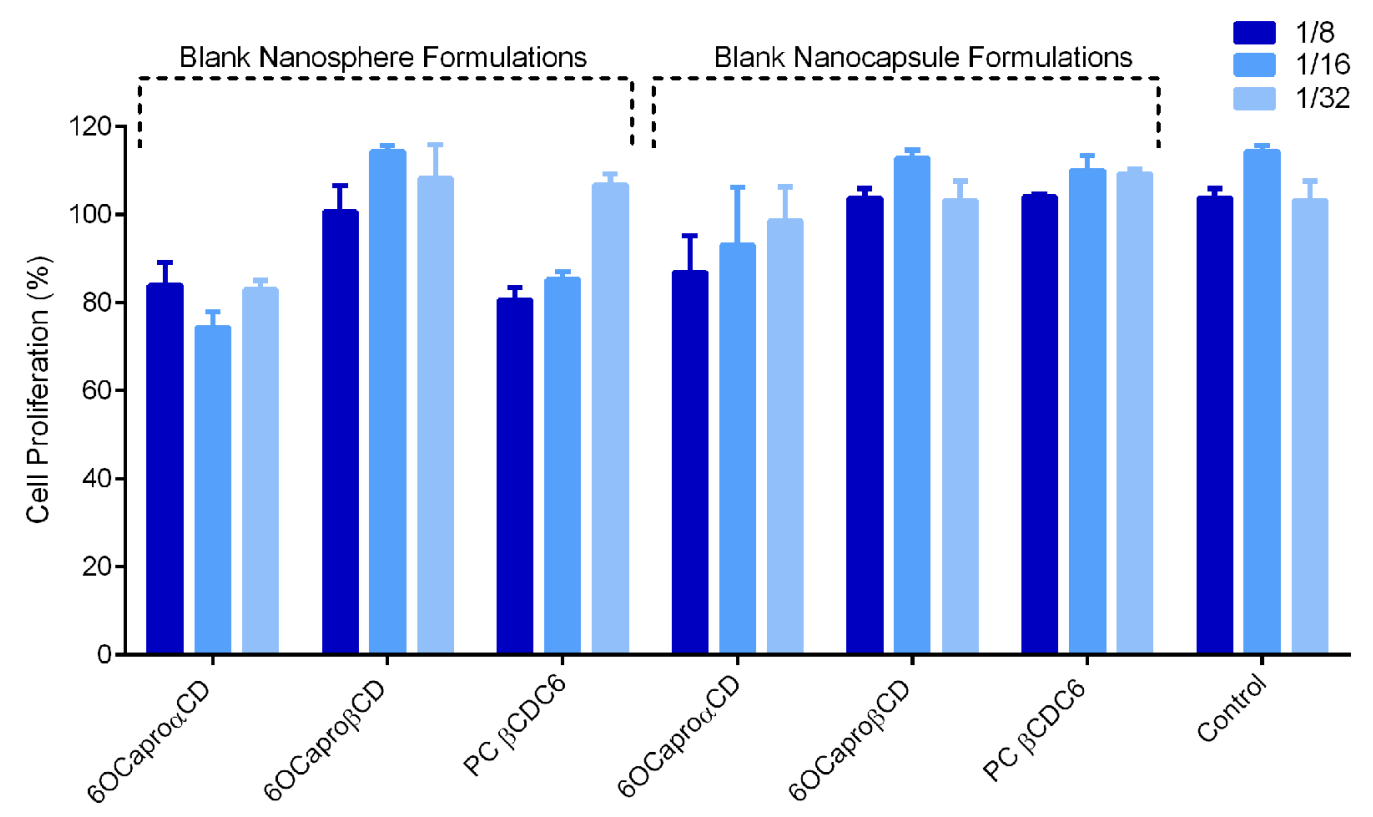

Figure 4. Effect of different blank amphiphilic CD nanoparticles on the proliferation of healthy L929 mouse fibroblast cells $(n=4, \pm S D)$ 
a

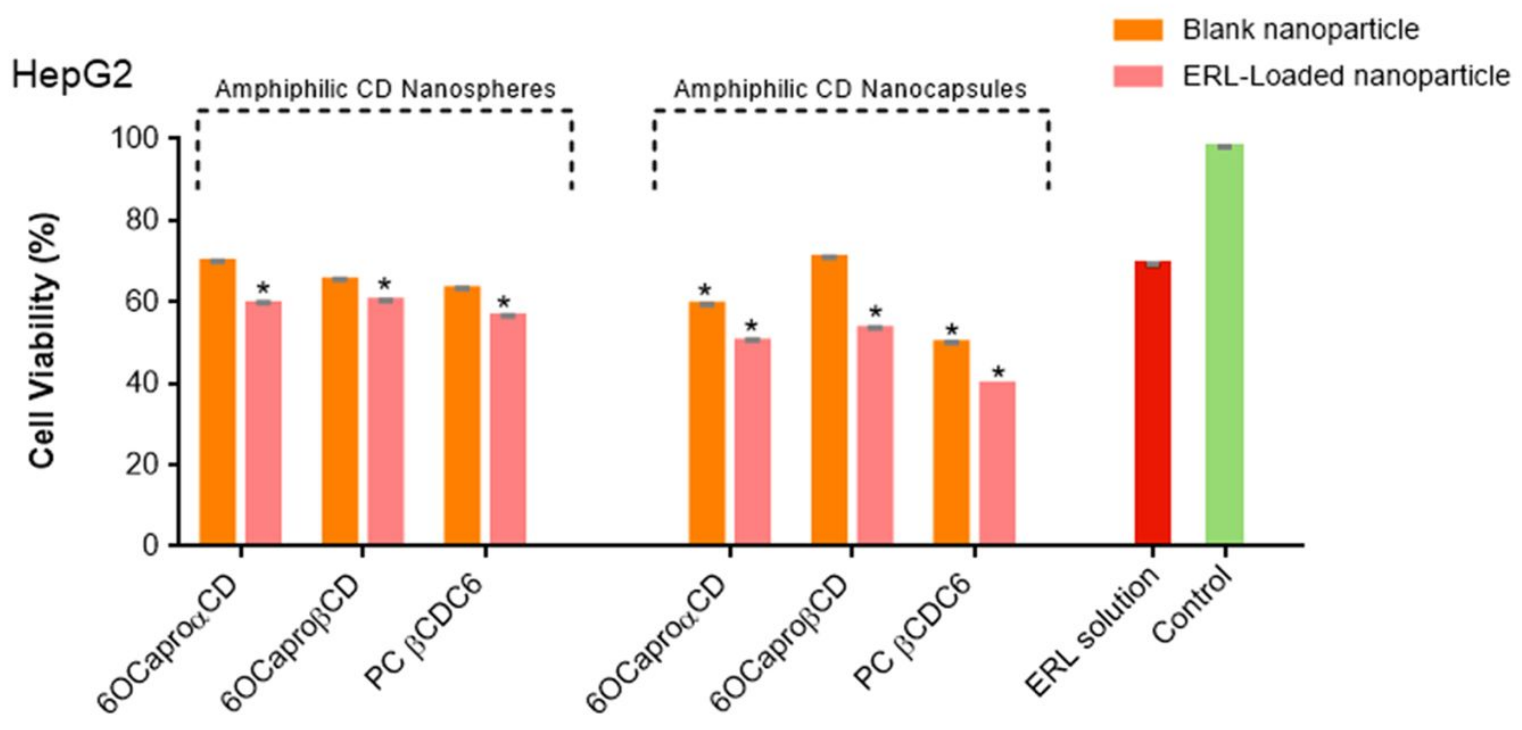

b

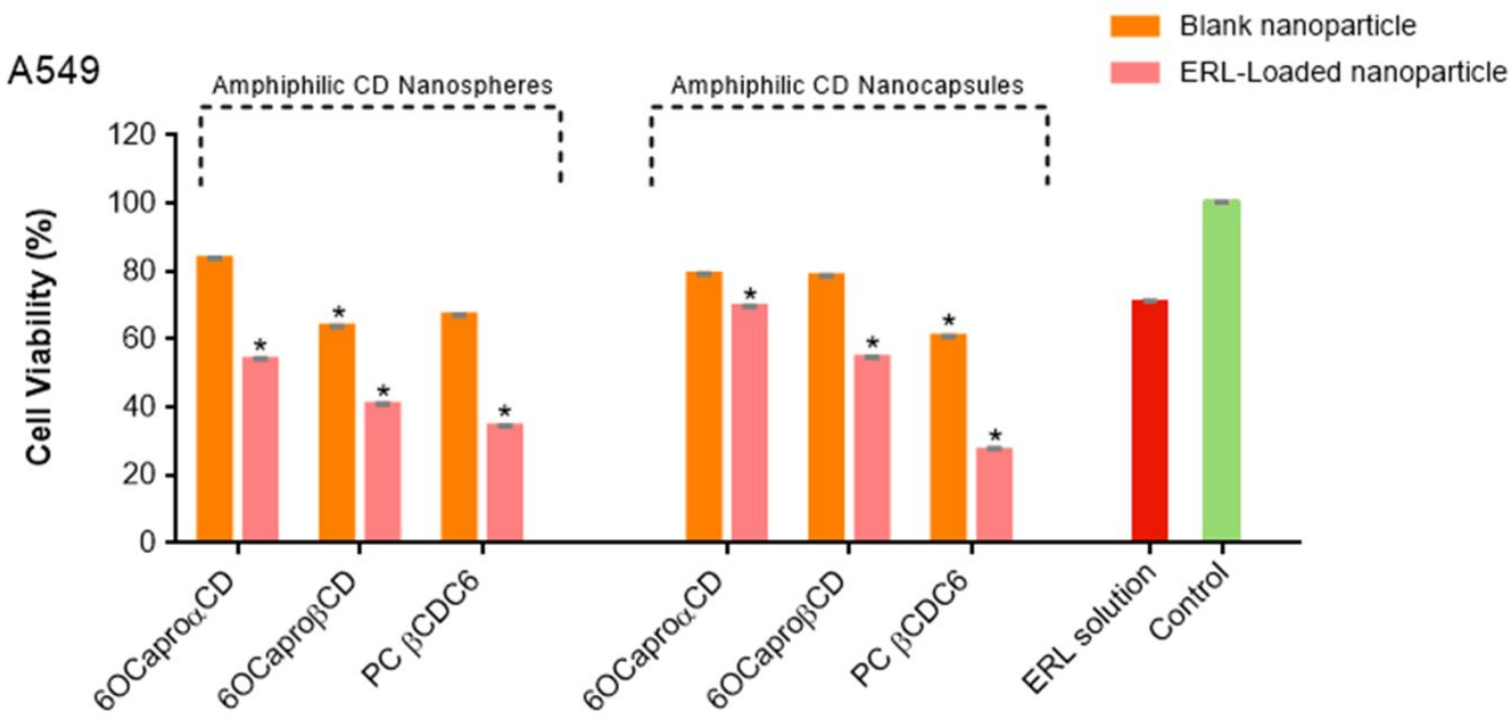

Figure 5. Antiproliferative effect of blank and ERL-loaded amphiphilic CD nanospheres and nanocapsules against 2D HepG2 hepatocellular carcinoma cell line (a) and 2D A459 non-small cell lung cancer cell line (b) $(n=4 ; \pm S D) . * p<0.05$ compared with ERL solution 


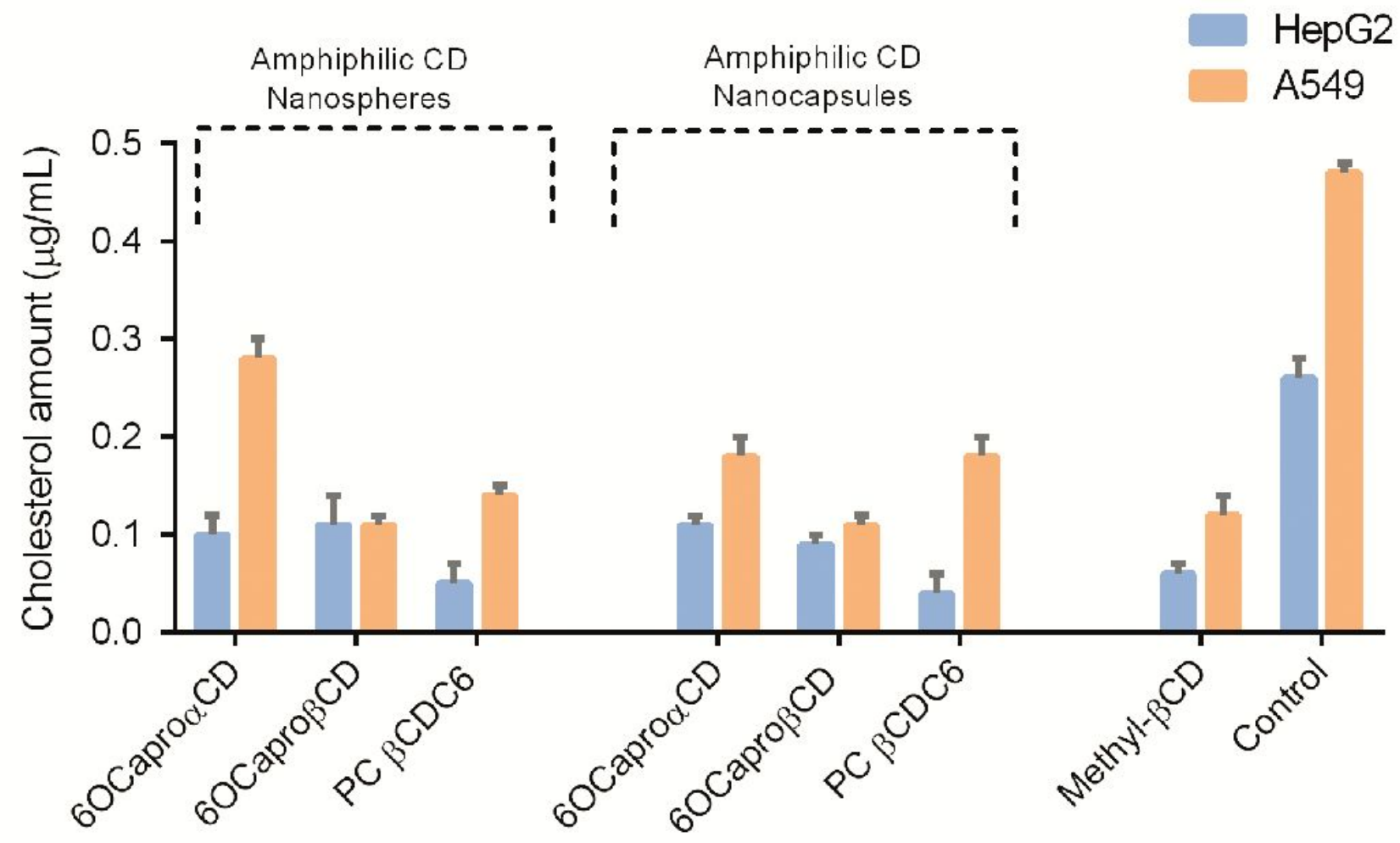

Figure 6. Total cellular cholesterol amount of A549 and HepG2 cells treated with blank amphiphilic cyclodextrin nanoparticles in 24 hours $(n=4 ; \pm S D)$. 
a

\section{HepG2}

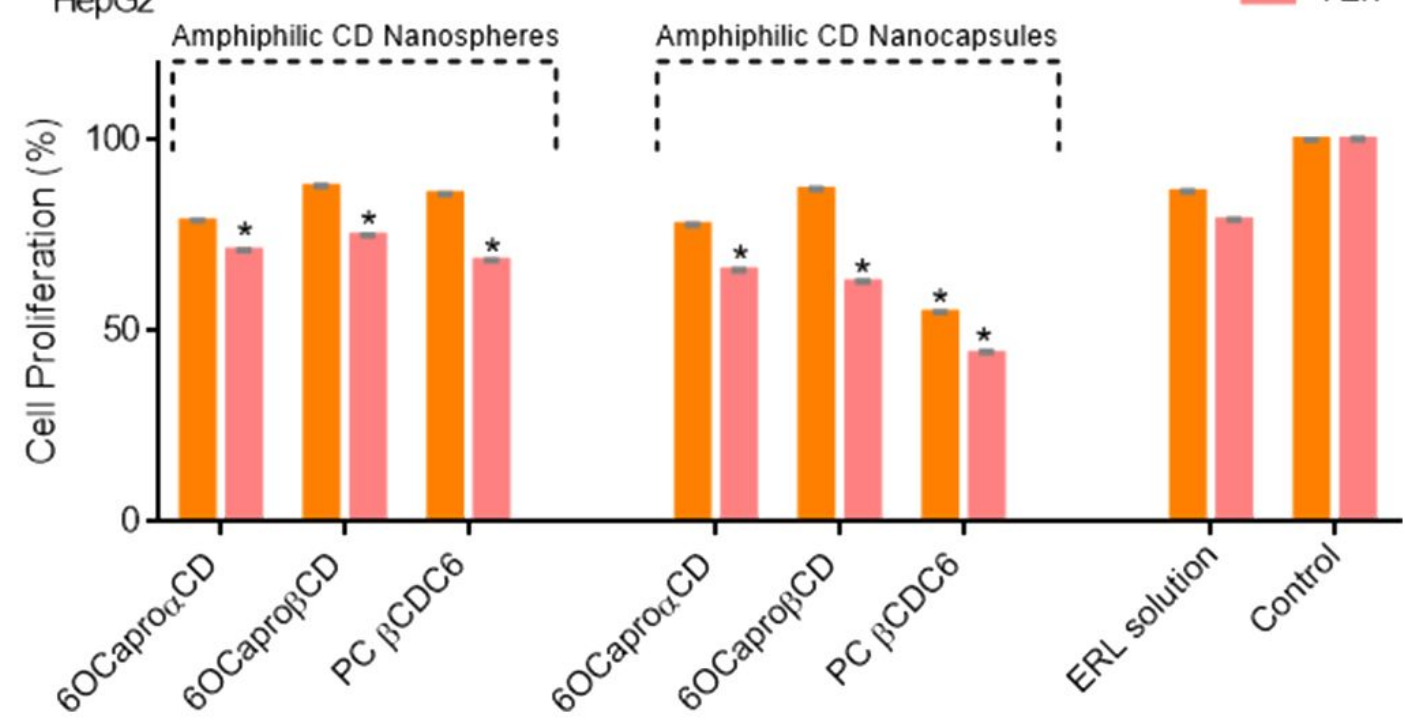

b

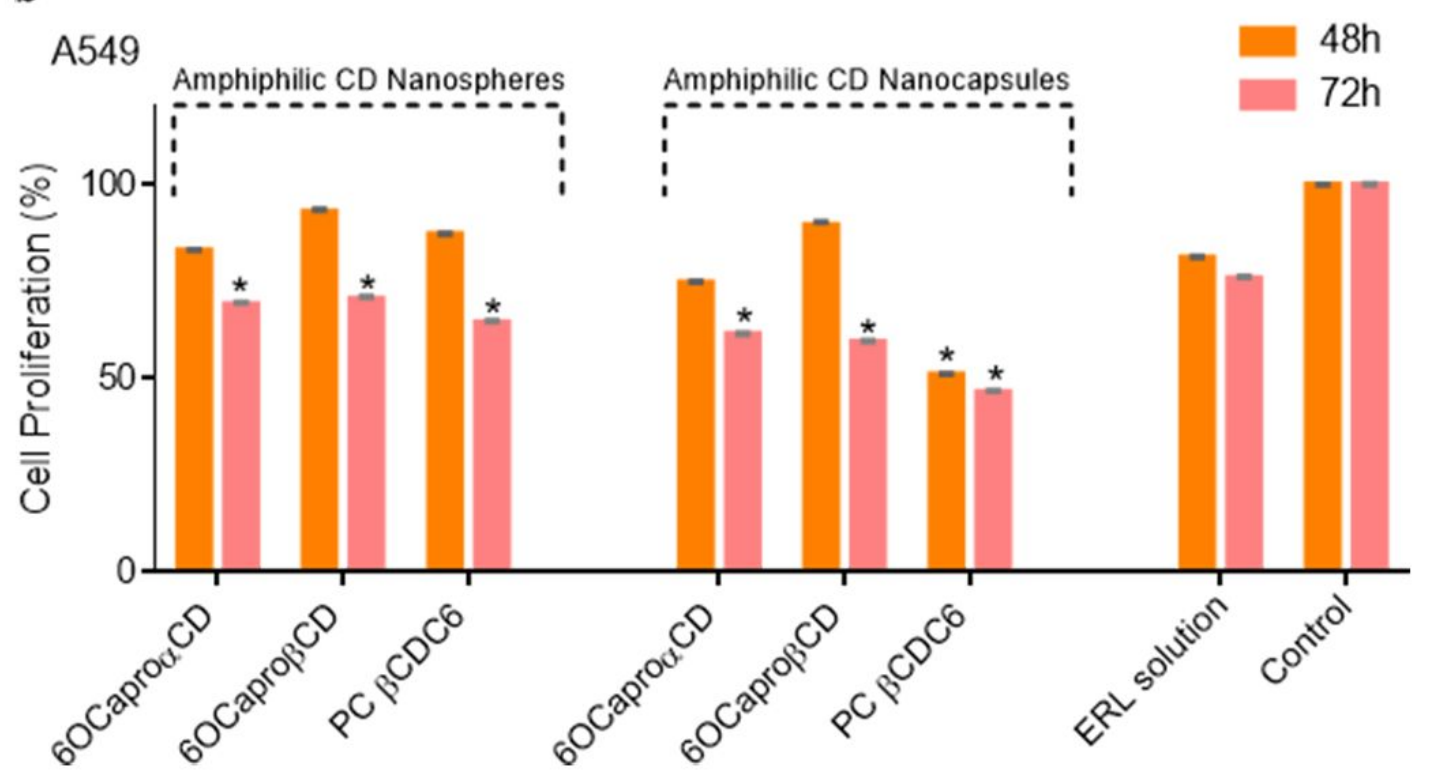

Figure 7. Antitumor effect of ERL-loaded amphiphilic CD nanospheres and nanocapsules against $3 D$ HepG2 (a) and A549 (b) cell line $(n=4 ; \pm S D) .{ }^{*} p<0.05$ compared with ERL solution 


\section{Nile Red loaded 60CaproaCD Nanosphere \\ Nile Red loaded 60CaproaCD Nanocapsule}

Nile Red loaded 6OCaproßCD Nanosphere

Nile Red loaded 6OCaproßCD Nanocapsule

Nile Red loaded PC $\beta C D C 6$ Nanosphere

Nile Red loaded PC $\beta$ CDC6 Nanocapsule

Nile Red Sol.
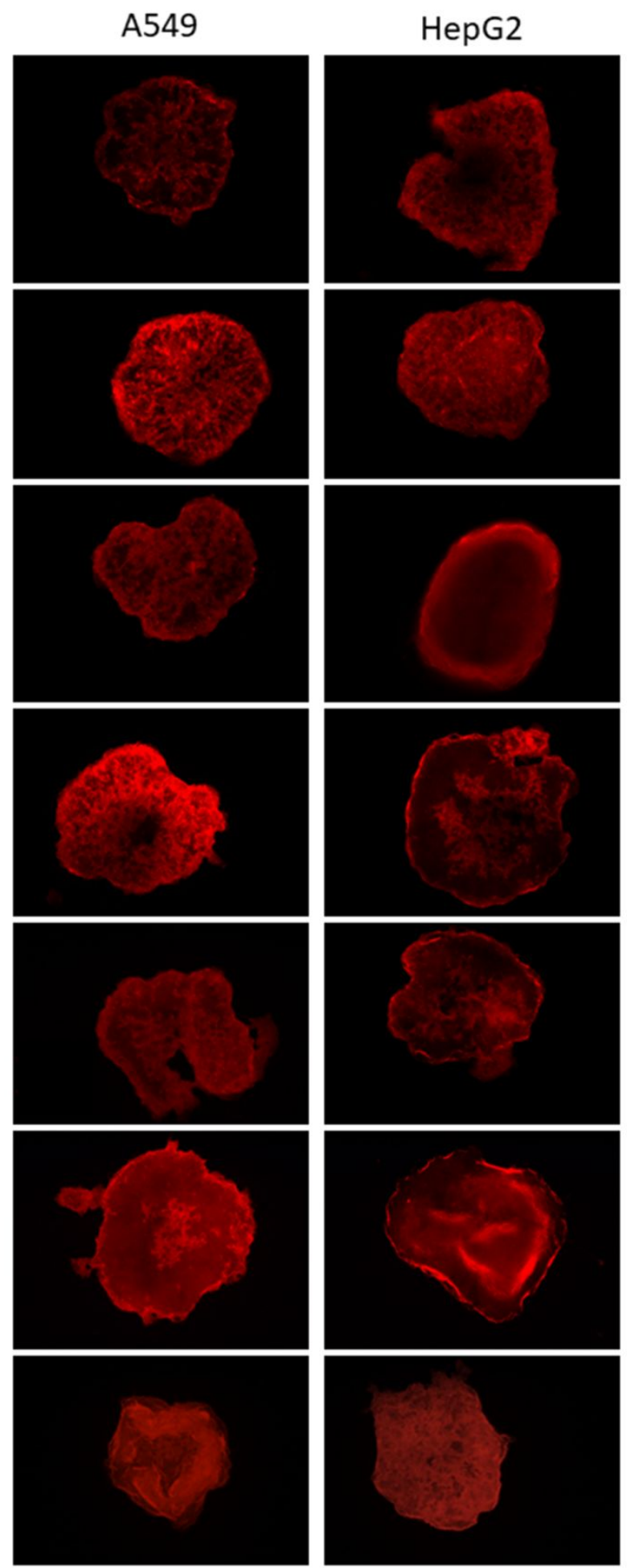

Figure 8. Tumoral penetration of Nile red-loaded amphiphilic nanospheres and nanocapsules into $3 D A 549$ and $3 D$ HepG2 spherical tumors. 
Table 1. Averaged hydrodynamic diameter (nm), polydispersity index and zeta potential (mV) measurement of blank and ERL-loaded amphiphilic CD nanospheres and nanocapsules $(n=3, \pm S D)$

\begin{tabular}{|c|c|c|c|c|}
\hline & $\begin{array}{c}\text { Amphiphilic } \\
\text { CD Derivatives }\end{array}$ & $\begin{array}{c}\text { Particle Size } \\
\text { (nm) }\end{array}$ & PDI & $\begin{array}{c}\text { Zeta Potential } \\
(\mathrm{mV})\end{array}$ \\
\hline \multirow{3}{*}{$\begin{array}{c}\text { Blank Nanosphere } \\
\text { Formulations }\end{array}$} & 60CaproßCD & $173 \pm 15$ & $0.1 \pm 0.1$ & $-26.5 \pm 3.1$ \\
\hline & 6OCaproaCD & $272 \pm 12$ & $0.2 \pm 0.2$ & $-18.5 \pm 0.4$ \\
\hline & РC $\beta$ CDC6 & $121 \pm 17$ & $0.3 \pm 0.1$ & $+73 \pm 4.8$ \\
\hline \multirow{3}{*}{$\begin{array}{c}\text { Blank Nanocapsule } \\
\text { Formulations }\end{array}$} & 60Capro $\beta C D$ & $264 \pm 9.6$ & $0.15 \pm 0.02$ & $-34.2 \pm 5.6$ \\
\hline & 6OCaproaCD & $310 \pm 25$ & $0.18 \pm 0.07$ & $-28.6 \pm 2.3$ \\
\hline & РC $\beta C D C 6$ & $259 \pm 17.2$ & $0.18 \pm 0.1$ & $+75.2 \pm 4$ \\
\hline \multirow{3}{*}{$\begin{array}{c}\text { ERL-Loaded Nanosphere } \\
\text { Formulations }\end{array}$} & 60CaproßCD & $145 \pm 11$ & $0.09 \pm 0.05$ & $-27.3 \pm 6$ \\
\hline & 6OCaproaCD & $187 \pm 11$ & $0.18 \pm 0.03$ & $-19.2 \pm 3$ \\
\hline & РC $\beta$ CDC6 & $88 \pm 9$ & $0.13 \pm 0.05$ & $+62.1 \pm 5$ \\
\hline \multirow{3}{*}{$\begin{array}{c}\text { ERL-Loaded Nanocapsule } \\
\text { Formulations }\end{array}$} & 60CaproßCD & $262 \pm 20$ & $0.16 \pm 0.02$ & $-28.5 \pm 10$ \\
\hline & 6OCaproaCD & $270 \pm 7$ & $0.11 \pm 0.02$ & $-32.3 \pm 2$ \\
\hline & PC $\beta C D C 6$ & $152 \pm 8$ & $0.09 \pm 0.01$ & $+74.9 \pm 7$ \\
\hline
\end{tabular}


Table 2. IC ${ }_{50}$ values $(\mu M)$ of ERL solution and ERL-loaded nanoparticle formulations on cancer cell lines A549 (lung) and HepG2 (liver) for 24 and $48 h(n=3, \pm S D)\left({ }^{*} p<0.05\right.$ compared with ERL solution)

\begin{tabular}{|c|c|c|c|c|}
\hline \multirow{2}{*}{ Formulation } & \multicolumn{2}{|c|}{ A549 } & \multicolumn{2}{|c|}{ HepG2 } \\
\hline & $24 \mathrm{~h}$ & $48 \mathrm{~h}$ & $24 \mathrm{~h}$ & $48 \mathrm{~h}$ \\
\hline 6OCaproaCD nanosphere & $14.2 \pm 3.2$ & $1.9 \pm 0.2^{*}$ & $9.0 \pm 0.1$ & $2.2 \pm 0.3^{*}$ \\
\hline 6OCaproaCD nanocapsule & $8.5 \pm 0.1$ & $2.7 \pm 0.1^{*}$ & $3.4 \pm 1.1$ & $2.3 \pm 0.8^{*}$ \\
\hline 6OCaproßCD nanosphere & $5.1 \pm 2.1$ & $3.2 \pm 0.4^{*}$ & $4.7 \pm 1.2$ & $3.1 \pm 0.2^{*}$ \\
\hline 6OCaproßCD nanocapsule & $7.9 \pm 2.3$ & $2.8 \pm 0.5^{*}$ & $3.9 \pm 0.2^{*}$ & $2.6 \pm 0.3^{*}$ \\
\hline PC $\beta C D C 6$ nanosphere & $6.5 \pm 1.2$ & $2.1 \pm 1.3^{*}$ & $3.1 \pm 1.4^{*}$ & $1.1 \pm 0.2^{*}$ \\
\hline PC $\beta C D C 6$ nanocapsule & $4.6 \pm 0.2^{*}$ & $1.5 \pm 0.1^{*}$ & $1.6 \pm 0.8^{*}$ & $0.2 \pm 0.1^{*}$ \\
\hline Erlotinib solution & $8.2 \pm 2.0$ & $5.1 \pm 1.2$ & $4.8 \pm 0.3$ & $3.8 \pm 0.1$ \\
\hline
\end{tabular}




\section{Supplemental file: Synthesis and characterization of amphiphilic 60CaproaCD}

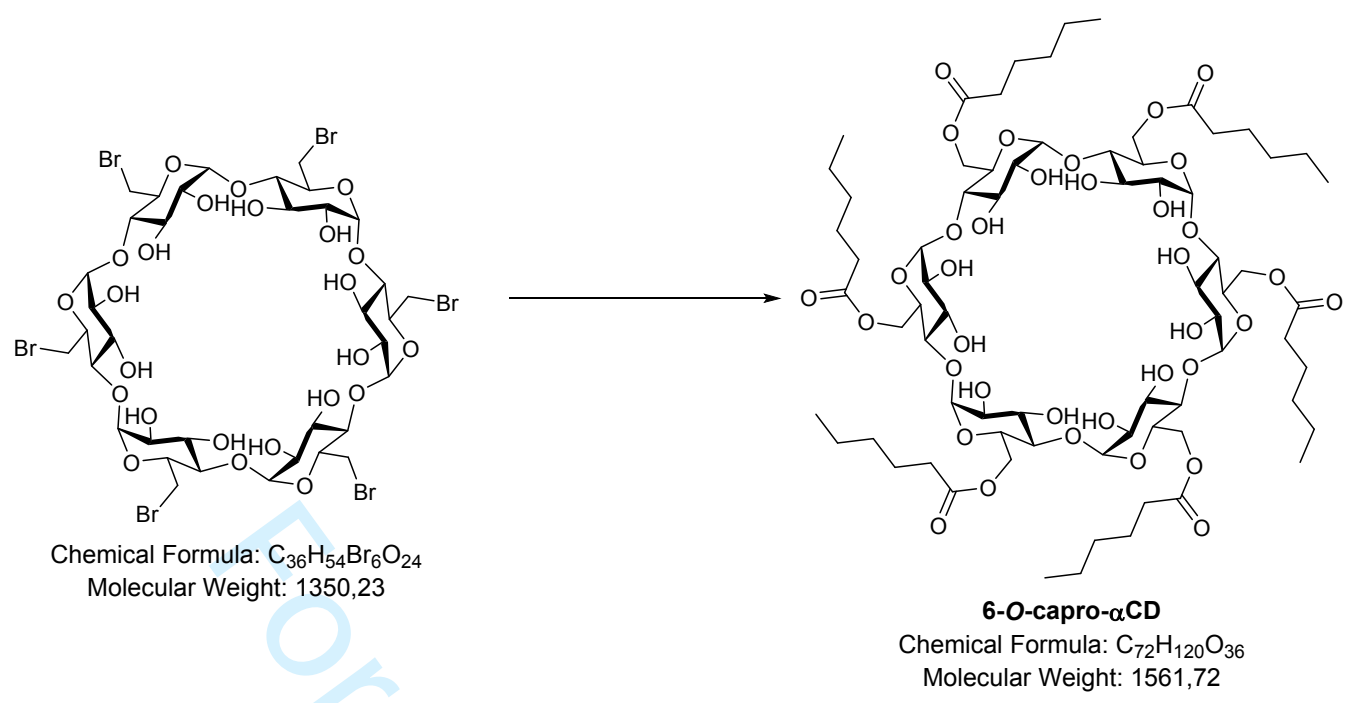

Figure 1. Molecular structure of amphiphilic amphiphilic 6OCaproaCD

Hexakis(6-hexanoyl)cyclomaltoheptaose. A solution of hexakis(6-bromo-6deoxy)cyclomaltoheptaose ${ }^{1}(3.57 \mathrm{~g}, 2.6 \mathrm{mmol})$ in anhydrous DMF $(50 \mathrm{~mL})$ stirred under $\operatorname{Ar}\left(\operatorname{or} \mathrm{N}_{2}\right.$ ) atmosphere was dropwise cannulated over $1 \mathrm{~h}$ to a suspension of hexanoic acid $(3.0 \mathrm{~mL} \mathrm{~g}, 2.76 \mathrm{~g}, 23.8 \mathrm{mmol}, 1.5 \mathrm{eq})$ and $\mathrm{Cs}_{2} \mathrm{CO}_{3}(7.73 \mathrm{~g}, 23.8 \mathrm{mmol}, 1.5 \mathrm{eq})$ in anhydrous DMF $\left(50 \mathrm{~mL}\right.$ ) under $\operatorname{Ar}\left(\right.$ or $\mathrm{N}_{2}$ ). Then, the mixture was gently warmed up to $60 \stackrel{\circ}{ } \mathrm{C}$ and stirred for $16 \mathrm{~h}$. The resulting suspension was concentrated until no more DMF distilled off and the syrupy residue was then suspended in water $(200 \mathrm{~mL})$. A white solid precipitated off upon stirring for $30 \mathrm{~min}$ and further collected by filtration. The slurry was re-suspended in acetone $(100 \mathrm{~mL})$ and the precipitate was again collected by filtration and dried under reduced pressure to afford the target compound in 59\% yield ( $3.30 \mathrm{gr}$ ) as a white solid. Purity and identity of the product was assessed by ${ }^{1} \mathrm{H}-,{ }^{13} \mathrm{C}$ NMR and MS. ${ }^{1} \mathrm{H}$ NMR (400 MHz, 1:10 MeOD-DMSO- $\left.d_{6}\right): \delta 4.84\left(\mathrm{~d}, 6 \mathrm{H}, J_{1,2}=3.3 \mathrm{~Hz}, \mathrm{H}-\right.$ 1), $4.28\left(\mathrm{bd}, 6 \mathrm{H}, J_{6 a, 6 b}=11.2 \mathrm{~Hz}, \mathrm{H}-6 \mathrm{a}\right), 4.22\left(\mathrm{dd}, 6 \mathrm{H}, J_{5,6 b}=6.0 \mathrm{~Hz}, \mathrm{H}-6 \mathrm{~b}\right), 3.94(\mathrm{~m}, 6 \mathrm{H}$, $\mathrm{H}-5), 3.78\left(\mathrm{t}, 6 \mathrm{H}, J_{2,3}=J_{3,4}=9.0 \mathrm{~Hz}, \mathrm{H}-3\right), 3.41\left(\mathrm{t}, 6 \mathrm{H}, J_{4,5}=8.8 \mathrm{~Hz}, \mathrm{H}-4\right), 3.34(\mathrm{dd}, 6 \mathrm{H}, \mathrm{H}-$ 2), 2.30, $2.23\left(2 \mathrm{~m}, 12 \mathrm{H},{ }^{3} \mathrm{~J}_{\mathrm{H}, \mathrm{H}}=7.4 \mathrm{~Hz}, \mathrm{CH}_{2} \mathrm{CO}\right), 1.50\left(\mathrm{~m}, 12 \mathrm{H}, \mathrm{CH}_{2} \mathrm{CH}_{2} \mathrm{CO}\right), 1.25(\mathrm{~m}, 24 \mathrm{H}$, $\left.\mathrm{CH}_{3} \mathrm{CH}_{2} \mathrm{CH}_{2}\right), 0.85\left(\mathrm{t}, 18 \mathrm{H}, \mathrm{CH}_{3} \mathrm{CH}_{2}\right) .{ }^{13} \mathrm{C}$ NMR (100.6 MHz, DMSO-d $\left.d_{6}\right): \delta 173.1$ (CO), 102.3

\footnotetext{
${ }^{1}$ H. H. Baer, A. Vargas Berenguel, Y. Y. Shu, J. Defaye, A. Gadelle, F. Santoyo Gonzalez, Carbohydr. Res. 1992, 228, 307-314.
} 
(C-1), 82.8 (C-4), 73.5, 72.3 (C-2,3), 69.7 (C-5), 63.5 (C-6), $33.6\left(\mathrm{CH}_{2} \mathrm{CO}\right)$ 31.1, 24.6 $\left(\mathrm{CH}_{2} \mathrm{CH}_{2}\right), 22.3\left(\mathrm{CH}_{2} \mathrm{CH}_{3}\right), 14.2\left(\mathrm{CH}_{3}\right)$. ESI-MS $(\mathrm{m} / \mathrm{z}): 1583.8\left([\mathrm{M}+\mathrm{Na}]^{+}\right), 1559.6\left([\mathrm{M}-\mathrm{H}]^{-}\right)$.

\section{${ }^{1} \mathrm{H}$ NMR (10:1 MeOD-DMSO- $\left.d_{6}\right)$}

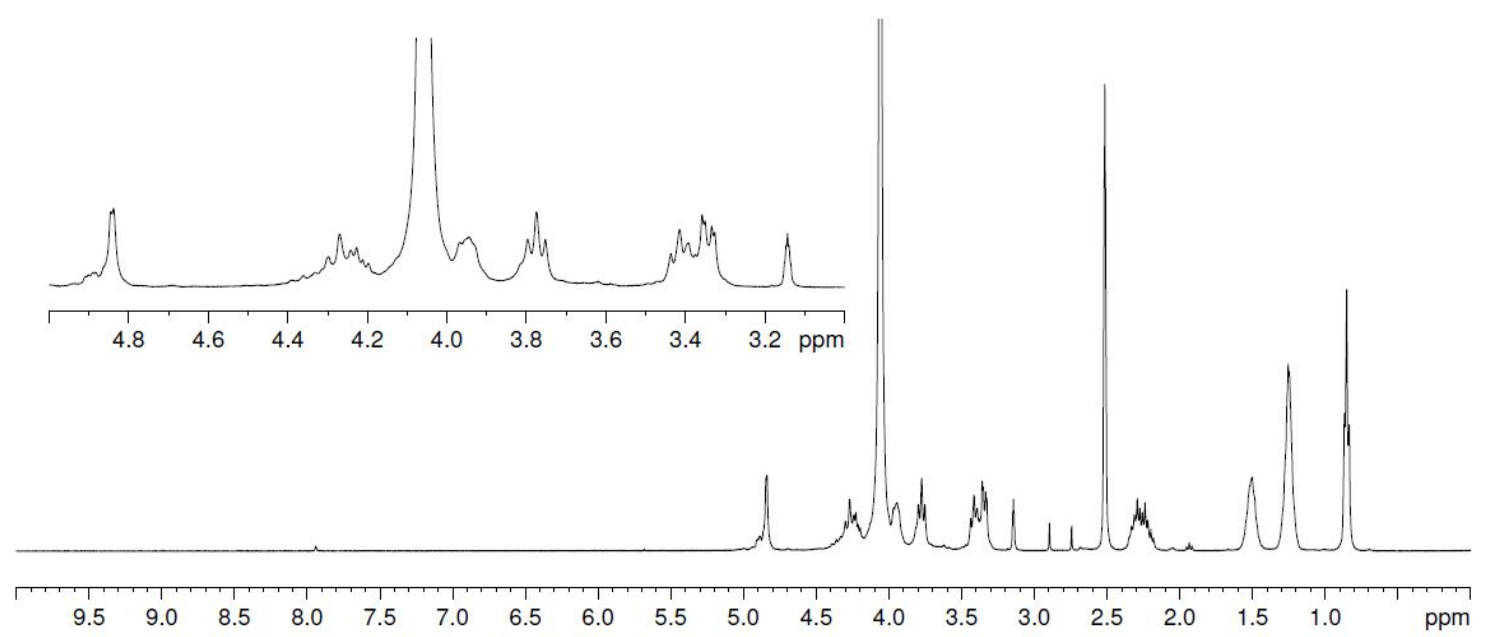

\section{${ }^{13}$ C NMR (DMSO- $\left.d_{6}\right)$}

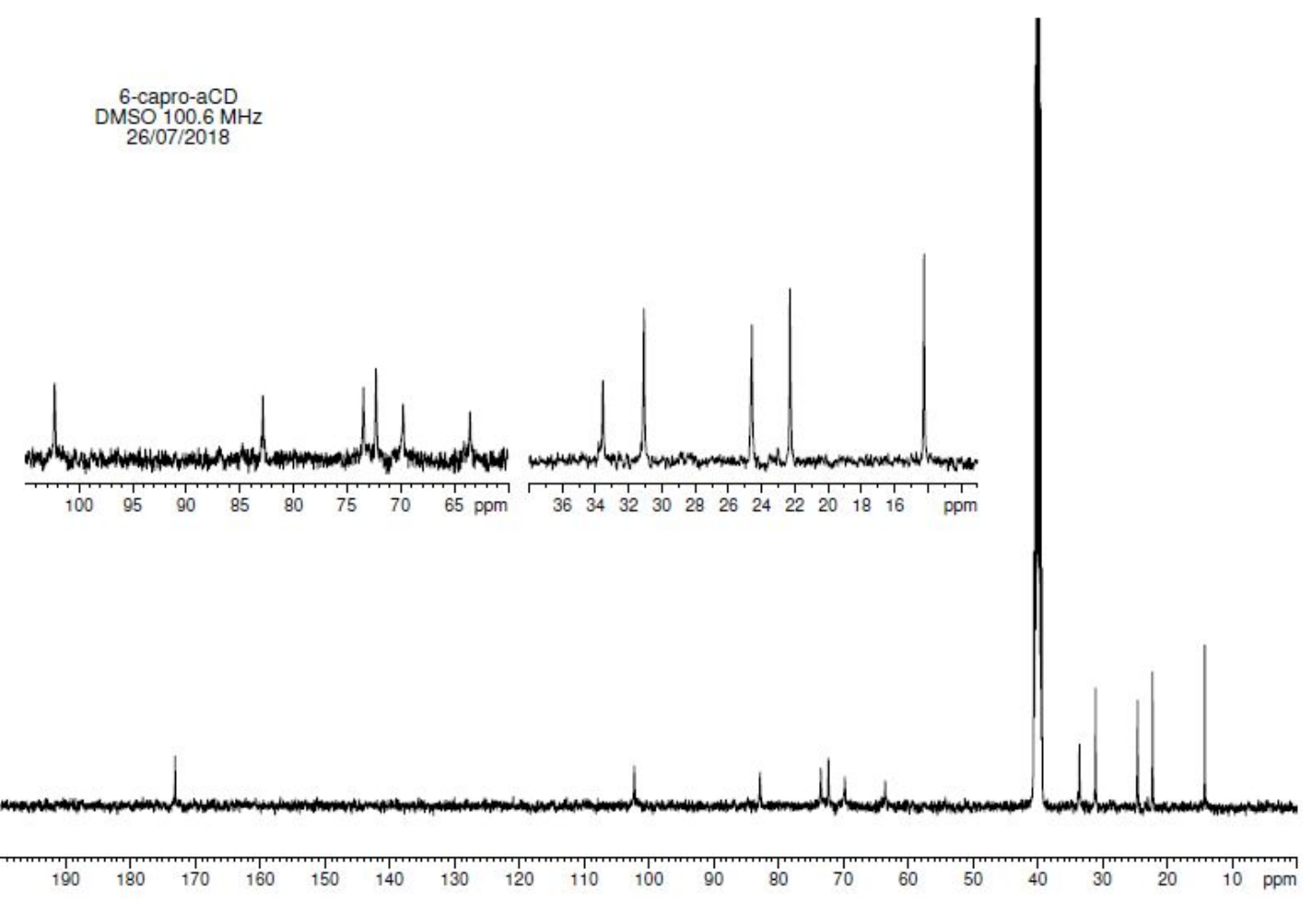




\section{ESI-MS spectra}

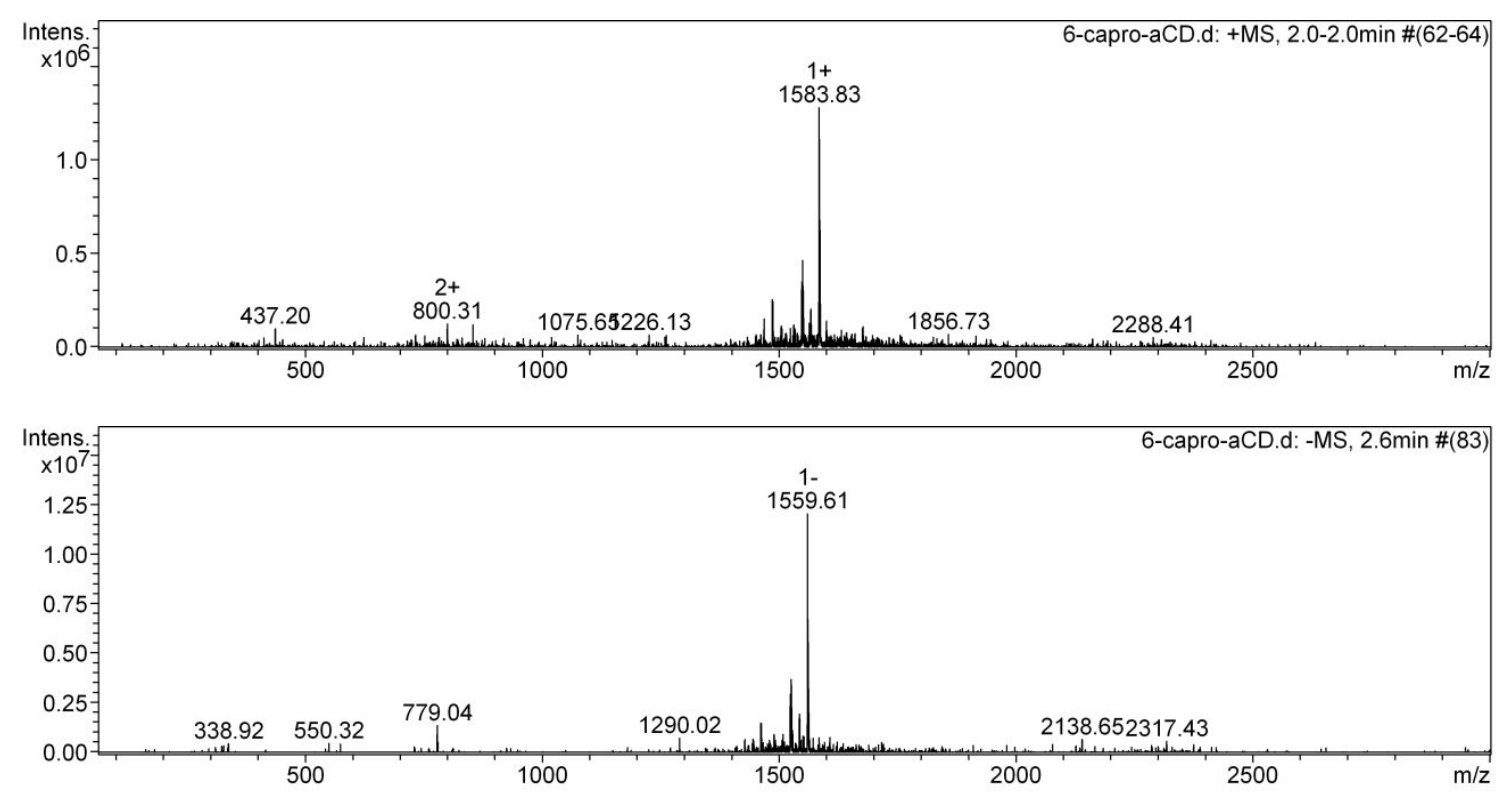

